Check for updates

Cite this: RSC Adv., 2020, 10, 36989

\title{
Natural deep eutectic solvent supported targeted solid-liquid polymer carrier for breast cancer therapy $\dagger$
}

\author{
Xianfu Sun, ${ }^{a}$ Periyakaruppan Pradeepkumar, ${ }^{* b}$ Naresh Kumar Rajendran, ${ }^{c}$ \\ Harshavardhan Shakila, ${ }^{d}$ Nicolette Nadene Houreld, ${ }^{C}$ Dunia A. Al Farraj, ${ }^{e}$ \\ Yousif M. Elnahas, ${ }^{f}$ Nandhakumar Elumalai ${ }^{9}$ and Mariappan Rajan (DD $* b$
}

\begin{abstract}
Solid-liquid nanocarriers (SLNs) are at the front of the rapidly emerging field of medicinal applications with a potential role in the delivery of bioactive agents. Here, we report a new SLN of natural deep eutectic solvent (NADES) and biotin-conjugated lysine-polyethylene glycol copolymer. The SLN system was analyzed for its functional groups, thermal stability, crystalline nature, particle size, and surface morphology through the instrumental analysis of FT-IR, TGA, XRD, DLS, SEM, and TEM. Encapsulation of PTX (paclitaxel) and 7-HC (7-hydroxycoumarin) with the SLN was carried out by dialysis, and UV-visible spectra evidenced the drug loading capacity and higher encapsulation efficiency obtained. The enhanced anticancer potential of PTX- and 7-HC-loaded SLN was assessed in vitro, and the system reduces the cell viability of MDA-MB-231 cells. The PTX- and 7-HC-loaded SLN system was investigated in a breast cancer-induced rat model via in vivo studies. It shows decreased lysosomal enzymes and increased levels of caspase to cure breast tumors. It very well may be reasoned that the designed PTXand 7-HC-loaded SLN system has strong anticancer properties and exhibits potential for delivery of drug molecules in cancer treatment.
\end{abstract}

Received 27th April 2020

Accepted 11th August 2020

DOI: $10.1039 / \mathrm{d} 0 \mathrm{ra03790g}$

rsc.li/rsc-advances

\section{Introduction}

Recent research development in medicinal applications has advanced through the improvement of new methods and materials that are more biodegradable, biocompatible, and less toxic. $^{1,2}$ There is an enormous attempt to explore the role/ function of synthetic biomaterials used in drug delivery applications. ${ }^{3}$ Currently, synthetic and natural polymers, metal complexes, peptides, proteins, and hydrogels are used for the development of anticancer drug delivery systems, ${ }^{4-8}$ which

${ }^{a}$ Department of Breast, The Affiliated Tumor Hospital of Zhengzhou University, Zhengzhou, Henan, 450008, China

${ }^{b}$ Biomaterials in Medicinal Chemistry Laboratory, Department of Natural Products Chemistry, School of Chemistry, Madurai Kamaraj University, Madurai-625021, Tamil Nadu, India. E-mail: rajanm153@gmail.com

${ }^{c}$ Laser Research Centre, Faculty of Health Sciences, University of Johannesburg, PO Box 17011, Doornfontein 2028, South Africa

${ }^{d}$ Department of Molecular Microbiology, School of Biotechnology, Madurai Kamaraj University, Madurai-625021, India

${ }^{e}$ Department of Botany and Microbiology, College of Science, King Saud University, Riyadh 11451, Saudi Arabia

${ }^{f}$ Department of Surgery, College of Medicine, King Saud University Medical City, King Saud University, Riyadh, Saudi Arabia

${ }^{g}$ Department of Biochemistry, Sri Muthukumaran Medical College and Research Institute, Chennai-600069, Tamil Nadu, India

$\dagger$ Electronic supplementary information (ESI) available. See DOI: 10.1039/d0ra03790g reduce some disadvantages over conventional anticancer treatments such as poor solubility, low biodegradability, toxic nature, and poor intracellular penetration, retention time and sustainable release of encapsulated drugs. ${ }^{9}$ A significant number of nanoparticles such as inorganic nanoparticles or other polymeric/liquid nanoparticles have also been used in developing drug carrier systems. The drug carrier leads to the fabrication of a nanocarrier, and most of these are made up of synthetic polymers and not liquid-based carriers. ${ }^{10}$

Researchers have paid more attention to the advancement of new carrier systems by using ILs (ionic liquids) and DESs (deep eutectic solvents). ${ }^{11}$ Unfortunately, ILs and DESs have exhibited thermal instability, low drug loading levels, low drug release and solubility, and have a very weak interaction with and a toxic nature in biological systems. This issue can be overcome by the utilization of natural deep eutectic solvents (NADES). A NADES is a highly biocompatible material designed to serve as a carrier molecule that transports drugs to a specific site without any side effects; it is a non-toxic solvent prepared by secondary metabolites and does not affect the drug release mechanism. ${ }^{12}$ Secondary metabolites like phenolics, terpenoids, flavonoids, and other natural compounds are crucial for medicinal applications. ${ }^{13,14}$ Compared to organic solvents, the use of NADES has gained attention in the synthesis of carrier systems. ${ }^{15-18}$ 
Citrus limon peels are rich in bioactive compounds, including antioxidants, flavonoids, vitamins, and prolinebetaine (PB). PB is a natural bioactive compound, which has numerous biological properties, including antifungal, antibacterial, and anticancer activities. ${ }^{\mathbf{1 9 , 2 0}}$ Anticancer activity is an essential property of $\mathrm{PB}$ and is due to the presence of amine which is a highly reactive compound that can readily react with biological compound moieties such as hydroxyl groups. In this study, PB is isolated and used for the synthesis of NADES in combination with lactic acid (LA), which is an excellent electron donor/acceptor. The selfassembled drug carrier system with $\mathrm{PB}$ is reported to target tumor cells. ${ }^{21}$ However, there is the need for an extra efficient and active targeting ligand to achieve better cellular uptake of drugloaded carriers. Different ligands such as polysaccharides, folic acid, peptides, and biotin are involved in targeting drug carrier synthesis. ${ }^{22}$ Among these, biotin is predominantly utilized as a tumor-focusing group for numerous cancer chemotherapy applications. ${ }^{23}$ Tumor cells need vitamins for their survival, and speedily growing cancer cells overexpress the receptors for this vitamin on their cell surface.

This paper reports for the first time on the preparation of NADES using secondary metabolites, and it is used as a biotinconjugated solid-liquid nanocarrier (SLN) for the encapsulation of the anticancer drugs paclitaxel (PTX) and 7-hydroxycoumarin (7-HC). The advantage of SLNs is the ability to incorporate hydrophobic anticancer drugs in the inner core and hydrophilic anticancer drugs on the outer core. The incorporation of PTX and 7-HC in the SLN system will reduce side effects and improve bioavailability. The anticancer activity of the synthesized PTXand 7-HC-loaded SLN system was investigated in vitro in a MDAMB-231 breast cancer cell line, and in vivo in a DMBA-induced breast cancer rat model.

\section{Experimental section}

\section{Materials}

EDC (1-ethyl-3-(3-dimethylaminopropyl)carbodiimide), LA (lactic acid), NHS ( $N$-hydroxysuccinimide), $p$-TsOH ( $p$-toluenesulfonic acid), tin(II) 2-ethylhexanoate $\left(\mathrm{Sn}(\mathrm{Oct})_{2}\right)$, and 7,12dimethylbenz $[a]$ anthracene (DMBA) were procured from Sigma-Aldrich, Mumbai, India. Lysine, polyethylene glycol6000, biotin, PTX, and 7-HC were purchased from Merck, Mumbai, India. Petroleum ether (PE), dichloromethane (DCM), ethyl acetate (EA), diethyl ether (DE), methanol, acetone, acetonitrile (AN) and dimethyl sulfoxide (DMSO) were received from Himedia Laboratories Pvt. Ltd, Mumbai, India (HPLC grade). A human breast adenocarcinoma (MDA-MB-231) cell line and normal mouse fibroblast cell line (L929) obtained from the National Center for Cell Science, Pune, India were used for this work. Caspase colorimetric assay kit was from R and D Systems Inc., USA. The chemicals and solvents used were of analytical grade and main clarity. In all the experiments, double-distilled (DD) water was used as a solvent and washing solution. The other chemicals were purchased from the different companies like BDH Division (Mumbai, India), Glaxo Laboratories, Sisco Research Laboratories, Sarabhai Chemicals (Vadodara, India), and SD Fine Chemicals (Mumbai, India).

\section{Isolation of prolinebetaine from Citrus limon peels}

Citrus fruits (Citrus limon peels) were acquired from a nearby market at Madurai, Tamil Nadu, India. ${ }^{24}$ The fruits were cleaned with DD water and acetone. The fruit peels were chopped into little pieces and dried at room temperature $\left(27^{\circ} \mathrm{C}\right)$. Dried samples were powdered into fine particles utilizing a blender. Ground samples were then dissolved in various solvents such as petroleum ether, chloroform, ethyl acetate, methanol, acetonitrile, and water for solubility optimization. Samples were loaded onto a silica gel packed column (100-200 mesh). Pet ether was used for initial elution. Fractions were removed for primary compounds such as oils, fats, fatty acids, resin, and chlorophyll compounds. Solvents were recovered through vacuum rotary evaporation (Rotavapor $\AA$ R-300).

Fractions were collected and used for further analysis. Optimized and stabilized ethyl acetate and methanol in ratios of $70: 30$ and $50: 50$ were used for the collection of 4-hydroxyprolinebetaine and PB. The solvents from the collected samples were evaporated at room temperature $\left(27{ }^{\circ} \mathrm{C}\right)$. The derived compounds were identified by HPLC, ${ }^{1} \mathrm{H}$ - and ${ }^{13} \mathrm{C}-\mathrm{NMR}$, and FT-IR analysis.

\section{Synthesis of NADESs}

NADESs were prepared according to a previously reported method..$^{25}$ Isolated and purified PB and LA were mixed in molar ratios of $1: 1,1: 2,1: 3$, and $2: 1$ at $40{ }^{\circ} \mathrm{C}$. Mixtures were magnetically stirred until a transparent homogenous liquid was obtained. Afterward, the eutectic mixture was chilled to room temperature. Ratios of $1: 2$ and $1: 3$ formed a clear solution, while proportions of $1: 1$ and $2: 1$ did not create a clear solution, as is shown in ESI Fig. 1. $\dagger$ The formation of NADESs and the chemical structures were identified through ${ }^{1} \mathrm{H}$ and ${ }^{13} \mathrm{C}$ NMR and FT-IR spectroscopy, as shown in ESI Fig. 3 and $4 . \dagger$

\section{Synthesis of biotin-g-lysine}

Biotin grafted lysine was prepared by the condensation method and carried out in the presence of $\mathrm{EDC} \cdot \mathrm{HCl}$ and $\mathrm{NHS}$ as per previous literature. ${ }^{26}$ In general, biotin (0.2 g, $\left.0.00136 \mathrm{mmol}\right)$ and lysine $(0.33 \mathrm{~g}, 0.00136 \mathrm{mmol})$ were solubilized in DCM (15 $\mathrm{mL})$. To this mixture, $\mathrm{EDC} \cdot \mathrm{HCl}(0.168 \mathrm{~mL}, 0.00136 \mathrm{mmol})$ and NHS $(0.15 \mathrm{~g}, 0.00136 \mathrm{mmol})$ were added drop-wise. The $\mathrm{pH}$ of the reaction mixture was adjusted to pH 7.4 using $1 \mathrm{~N} \mathrm{NaOH}$ and stirred for $2 \mathrm{~h}$ at $45{ }^{\circ} \mathrm{C}$. Then, the reaction mixture was precipitated using an organic solvent (acetone). The precipitate was filtered using Whatman $(0.2 \mu \mathrm{m})$ filter paper and dried in a vacuum chamber. The obtained precipitate was dialyzed using a dialysis membrane (MWCO-12000) in DD water for $22 \mathrm{~h}$ to eliminate unreacted constituents.

\section{Synthesis of biotin- $g$-lysine-co-polyethylene glycol (biotin- $g$ - lysine-co-PEG)}

Typically, biotin- $g$-lysine ( $1 \mathrm{~g}, 0.00268 \mathrm{mmol}), p$-TsOH $(0.4 \mathrm{~g}$, $0.00268 \mathrm{mmol}$ ), and polyethylene glycol-6000 (1 g) in $50 \mathrm{~mL}$ toluene were placed in a double neck round reaction flask with a Dean-Stark apparatus. ${ }^{27}$ Then, $\mathrm{Sn}(\mathrm{Oct})_{2}(0.8 \mathrm{~mL}, 1.0857 \mathrm{mmol})$ 
was added drop-wise, and heated at $125{ }^{\circ} \mathrm{C}$ for $24 \mathrm{~h}$ to reflux the mixture with continuous stirring and elimination of water. The reaction mixture was cooled to room temperature $\left(27^{\circ} \mathrm{C}\right)$; subsequently, the reaction solution was dissolved in ether and filtered to remove by-products. A Soxhlet apparatus was used for polymer extraction for $24 \mathrm{~h}$ with an organic solvent (ethyl acetate). Then, the obtained crude product was dried in a vacuum and the chemical structure of biotin- $g$-lysine-co-PEG was confirmed through FT-IR spectroscopy.

\section{NADES-based biotin-conjugated solid-liquid polymer in solvent emulsion method}

NADES-based biotin-conjugated polymeric SLN was prepared by the method mentioned in our previous report. ${ }^{28}$ Initially, $1 \mathrm{~g}$ of biotin- $g$-lysine-co-PEG was dissolved in $1 \mathrm{~mL}$ of NADES. This reaction mixture was kept under continuous stirring for $1 \mathrm{~h}$ at room temperature until the mixture became a homogeneous solution and attained a viscous consistency. Nanocarriers were formed using dialysis in aqueous solution, following a previous report. ${ }^{29}$ Briefly, $100 \mathrm{mg}$ of NADES-biotin- $g$-lysine-co-PEG system was dispersed in $1 \mathrm{~mL}$ DMSO solution and the solution was placed into a dialysis bag and dialyzed against $250 \mathrm{~mL}$ of DD water for $24 \mathrm{~h}$ to eliminate the DMSO solvent. The separated SLN was used for further processing.

\section{Determination of self-assembly of carrier formation}

The critical nanocarrier concentration (CMC) value of NADESbased biotin-conjugated solid-liquid polymer nanocarrier was studied by fluorescence spectroscopy through pyrene as a fluorescent moiety. ${ }^{30}$ In brief, various concentrations of NADESbased biotin-conjugated solid-liquid polymer nanocarrier $(0.1 \mathrm{~mL}$ to $1.0 \mathrm{~mL})$ were dissolved in $10 \mathrm{~mL}$ of DMSO solution. Then, pyrene $(0.1 \mathrm{mg})$ was solubilized in $5 \mathrm{mg} \mathrm{mL} \mathrm{me}^{-1}$ methanol and added to each test container of NADES-based biotinconjugated solid-liquid polymer nanocarrier solution. The reaction solution was magnetically stirred at $27^{\circ} \mathrm{C}$ for 1 day, and solvents vaporized. Afterwards, $5 \mathrm{~mL}$ of distilled water was added individually in a sample tube. The fluorescence of every pyrene-containing NADES-based biotin-conjugated solid-liquid polymer nanocarrier solution was determined by emission spectra (spectrofluorometer, Shimadzu F-4500, Japan) at a wavelength of $472 \mathrm{~nm}$ at $21 \pm 1{ }^{\circ} \mathrm{C}$.

\section{Encapsulation efficiency (EE)}

The NADES-based biotin-conjugated solid-liquid polymer nanocarrier (100 mg) was taken in a $25 \mathrm{~mL}$ beaker and PTX $\left(20 \mathrm{mg} \mathrm{mL}^{-1}\right)$ and $7-\mathrm{HC}\left(20 \mathrm{mg} \mathrm{mL}^{-1}\right)$ dispersed in ethanol were added to the SLN and stirred for $1 \mathrm{~h}$ with a magnetic stirrer. For determining the drug encapsulation efficiency, the supernatant solution was collected at 10 min intervals and analyzed by UVvisible spectroscopy at $\lambda_{\max }$ values of $270 \mathrm{~nm}$ and $320 \mathrm{~nm}$ (Shimadzu UV 1800). ${ }^{16}$ EE was calculated with the following equation: ${ }^{1}$
Encapsulation efficiency $(\%)$

$$
=\frac{\text { total amount of drug }- \text { free amount of drug }}{\text { total amount of drug }} \times 100
$$

\section{Drug release study}

The discharge of PTX and 7-HC from the nanocarrier was transferred to the dialysis system and a physiological buffer solution at $\mathrm{pH}$ values of $2.8,5.5$, and 7.4 was used at $27{ }^{\circ} \mathrm{C}$. Briefly, PTX- and 7-HC-loaded nanocarrier samples (30 mg) were added to $5 \mathrm{~mL}$ of fresh PBS ( $\mathrm{pH} 2.8,5.5$, and 7.4) in the dialysis bag at room temperature. The dialysis membrane was incubated in $50 \mathrm{~mL}$ PBS. PTX- and 7-HC-loaded SLN samples were stirred using a magnetic stirrer at a constant rate (100 rpm), and $3 \mathrm{~mL}$ of the supernatant solution was extracted at standard time intervals and supplemented with $3 \mathrm{~mL}$ of new buffer solution. Drugs released into the medium were quantified by a UV-visible spectrometer at $\lambda_{\max }$ values of $270 \mathrm{~nm}$ and $320 \mathrm{~nm}$ (Shimadzu 1600, Japan).

\section{Swelling studies}

The swelling behavior of PTX- and 7-HC-loaded SLN (30 mg) was analyzed in various buffer solutions at $\mathrm{pH} 2.8,5.5$, and 7.4 at room temperature $\left(27^{\circ} \mathrm{C}\right)$. At standard time intervals, samples were removed and weighed. A stable weight was achieved and the following equation was used to determine the swelling behavior:

$$
\text { Swelling }(\%)=\frac{W_{\mathrm{e}}-W_{\mathrm{d}}}{W_{\mathrm{d}}}
$$

where $W_{\mathrm{e}}$ and $W_{\mathrm{d}}$ are the weights of swollen polymer and dried nanocarriers, respectively.

\section{Biological characterizations}

Cell culture. A human breast adenocarcinoma cell line (MDA-MB-231) and a mouse fibroblast cell line (L929) were purchased from the NCCS (National Center for Cell Science, Pune, India). Cells were maintained in Dulbecco's modified Eagle's medium supplemented with $10 \%$ fetal bovine serum, and 1 unit per $\mathrm{mL}$ penicillin and $1 \mathrm{mg} \mathrm{mL}^{-1}$ streptomycin, and incubated at $37^{\circ} \mathrm{C}$ with $5 \% \mathrm{CO}_{2}$ in a humidified chamber. Cells were passaged every 3 to 4 days using trypsin/ ethylenediaminetetraacetic acid (EDTA) for detachment.

Cell viability. MDA-MB-231 human breast adenocarcinoma and L929 normal mouse fibroblast cells were used to interrogate the cytotoxic effect of PTX- and 7-HC-loaded and unloaded SLN system. Cells were seeded into 96-well plates at a seeding density of $1 \times 10^{5}$ cells per well and incubated for $24 \mathrm{~h}$ at $37^{\circ} \mathrm{C}$ in $5 \% \mathrm{CO}_{2}$. Various concentrations of PTX- and 7-HC-loaded SLN system $\left(10,25,50,75\right.$, and $\left.100 \mu \mathrm{g} \mathrm{mL}{ }^{-1}\right)$ were added to wells and cells were cultured for $24 \mathrm{~h}$. Afterwards, $25 \mu \mathrm{L}$ of MTT (3-(4,5-dimethylthiazol-2-yl)-2,5-diphenyltetrazolium bromide) assay solution was added to each well and incubated for $5 \mathrm{~h}$ at 
$37^{\circ} \mathrm{C}$. The cell culture medium was measured at an absorption wavelength of $570 \mathrm{~nm}$ using a microplate reader (SpectraMax M3, Molecular Devices, USA). The corresponding cell viability (\%) was correlated to normal cells. The following equation for cell viability was used for $\mathrm{IC}_{50}$ calculation:

$$
\begin{aligned}
\text { Cell viability }(\%)= & \frac{\mathrm{OD} \text { of the treated cells }}{\mathrm{OD} \text { of the untreated cells }(\text { control })} \\
& \times 100
\end{aligned}
$$

Mean OD of the untreated cells (control), is the mean of the untreated cells used as the control.

Cellular uptake analysis by confocal microscope. MDA-MB231 cells were cultured in 96-well plates and incubated with PTX- and 7-HC-loaded SLN for $24 \mathrm{~h}$. Cells were washed three times with PBS, fixed with 5\% paraformaldehyde for $30 \mathrm{~min}$, and stained with 4,6-diamidino-2-phenylindole (DAPI; $1 \mu \mathrm{g}$ $\mathrm{mL}^{-1}$ in PBS) for $10 \mathrm{~min}$. Cells were examined by confocal laser scanning microscopy (Olympus IX 81 under DU897 mode, Japan).

Animals and experimental design. Female Sprague-Dawley rats (eight weeks old) were separated into four groups, with each group having six animals. The regimen dose is shown in Table 1. All groups of animals had taken food and water, which was monitored daily for 14 days. A permanent amount of rat chow and fluid was given to every rat and refilled after that day. After treatment periods of 6 weeks, the rats were fasted for two nights, anesthetized and sacrificed by cervical decapitation. Whole blood samples were collected from both separations like plasma/serum, respectively. The mammary tissue was cut and washed in ice-cold saline and weighed. Tissue was cut up and homogenized with $0.1 \mathrm{M}$ Tris-HCl buffer ( $\mathrm{pH} 7.4$, and 10\%) and centrifuged $(3000 \times g$ for $10 \mathrm{~min})$. The finally obtained supernatant solution was used for enzyme assays. The bodyweights of the whole animals were recorded before and after the treatment and sacrifice.

The experimental work was performed with ethical norms approved by committee members of the Animals (CPCSEA), Ministry of Environment and Forests (Animal Welfare Division),
Government of India, and Institutional Animal Ethics Committee (IEAC) Guidelines.

Gross observations and tumor volume. The change in the body weight and tumor of animals was measured and recorded in grams. The following formula was used to calculate tumor volume:

$$
v=4 / 3 \pi r_{12} r_{2}\left(\text { radius } r_{1}<r_{2} ; r=\text { tumor diameter in } \mathrm{mm} / 2\right. \text { ) }
$$

Estimation of lysosomal marker enzymes. The enzymatic activity of acid phosphatase and cathepsin-D was evaluated as reported previously, ${ }^{31,32}$ and values were expressed as phenol/ protein min per $\mathrm{mg}$ and tyrosine/protein min per $\mathrm{mg}$, respectively. $\beta$-D-Glucuronidase was assayed by the method of Kawai and Anno, ${ }^{33}$ and the activity was expressed as $p$-nitrophenol $(\mu$ per moles) formed per min per mg protein.

Measurement of caspase-3, -8, and -9 activities. Caspase activation is a common apoptotic mechanism by which anticancer agents induce apoptosis. Hence, the level of caspase activation was determined for PTX- and 7-HC-loaded SLN system. The activities of caspase-3, -8 , and -9 were determined using a caspase colorimetric assay kit according to the manufacturer's recommended protocol ( $\mathrm{R}$ and D Systems Inc., USA). Spectrophotometric detection by the chromophore $p$-nitroanilide ( $p \mathrm{NA})$ assay was used for the cleavage from the labeled substrate that recognizes an optimal tetrapeptide sequence of the individual activation sites. Briefly, tissue homogenates were washed with ice-cold PBS, lysed with $50 \mu \mathrm{L}$ of cold lysis buffer and incubated on ice for $10 \mathrm{~min}$. Protein concentrations of the homogenates were assessed by the Bradford method, and 200 $\mu \mathrm{g}$ of protein was diluted in $50 \mu \mathrm{L}$ lysis buffer solution. In addition to that, $50 \mu \mathrm{L}$ of $2 \times$ reaction buffer (containing $10 \mathrm{mM}$ DTT) and $4 \mathrm{mM}$ DEVD- $p$ NA substrate were added to each sample well. After incubation at $27^{\circ} \mathrm{C}$ for $2 \mathrm{~h}$, samples were read at $405 \mathrm{~nm}$ using a microplate reader (BioTek, USA). Changes in caspase activity were determined by comparing these results with the level of control.

Table 1 Experimental animal groups and treatment conditions ${ }^{a}$

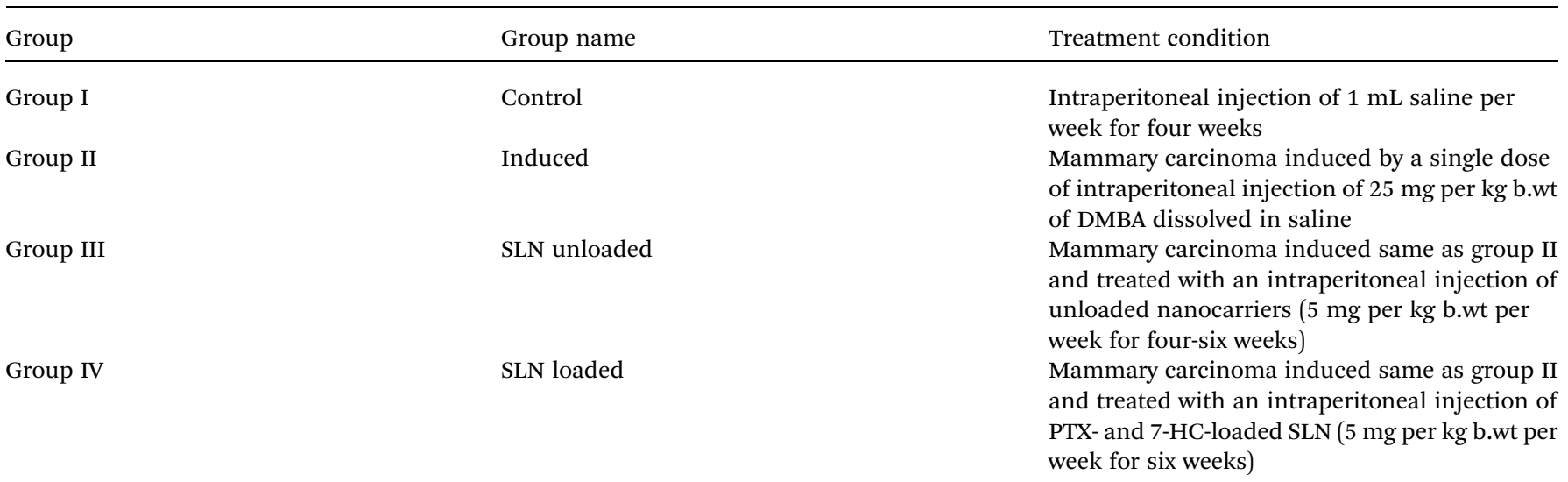

${ }^{a}$ b.wt, body weight; DMBA, 7,12-dimethylbenz[a]anthracene. 
Histopathological analysis. The evaluation of mammary and liver tissues preserved in formaldehyde (10\%) and embedded in paraffin was conducted through microscopic examination. The tissues were separated at 4-5 $\mu \mathrm{m}$ thickness via a semiautomated microtome and consequently stained with hematoxylin/eosin. Sections were viewed under a microscope (20× magnification).

\section{Statistical analysis}

The results were analyzed using a single way of variance, and whole results were obtained as mean \pm standard deviation (SD). All experimental work was performed in triplicate. Results with $* P<0.05$ were considered statistically significant.

\section{Results}

\section{Synthesis of NADES-supported biotin-conjugated solid-liquid polymer}

For the formulation of the NADES, 4-hydroxyprolinebetaine and $\mathrm{PB}$ were isolated from Citrus limon peels and identified by HPLC, ${ }^{1} \mathrm{H}-\mathrm{NMR},{ }^{13} \mathrm{C}-\mathrm{NMR}$, and FT-IR spectroscopy and the spectroscopic results were compared with those of previous reports. ${ }^{34}$ The purity of 4-hydroxyprolinebetaine and PB was identified by HPLC with $70: 30$ and $50: 50$ ratios of ethyl acetate/methanol solvent, respectively. The HPLC trace of the $70: 30$ ratio fractions revealed two peaks, one major peak and one minor peak. The major peak noted at a retention time (RT) of 25.6 corresponds to $\mathrm{PB}$, and the minor peak observed at a RT of 23.6 corresponds to 4-hydroxyprolinebetaine (ESI Fig. $2 \dagger$ ). These peaks were confirmed by standards and previously reported literature. ${ }^{34}$ Similarly, in the ethyl acetate/methanol $50: 50$ ratio fraction, the major peak was noted at a RT of 24.9, corresponding to PB.

The secondary metabolites $\mathrm{PB}$ and LA were used for the synthesis of NADESs with various ratios of $1: 1,1: 2,1: 3$, and $2: 1$. Ratios of $1: 2$ and $1: 3$ formed as a transparent solution, and the physicochemical properties were characterized, including the melting point and density of the solvents. NADES was created into exact molar ratios of the components to reach the eutectic point (Scheme 1A). NADES-based solid-liquid polymeric nanocarrier was synthesized by the interaction of free amine groups of the biotin- $g$-lysine-co-PEG polymer and - $\mathrm{OH}$ groups of the PB-LA solvent. The synthetic route of the NADESbased biotin- $g$-lysine-co-PEG polymer is given in Scheme $1 \mathrm{~A}$.

(A)

(B)<smiles>CC(O)C(=O)O</smiles>

I<smiles>CC(O)C(=O)O</smiles>

III

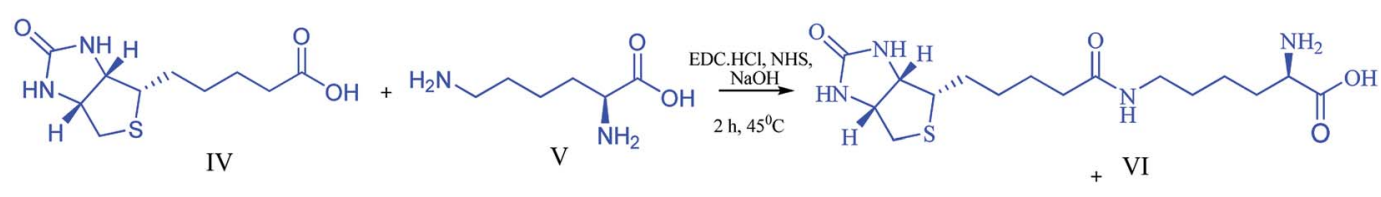

I. Proline betaine, II. Lactic acid III. NADES, IV. Biotin, V. Lysine VI. Biotin-g-lysine, VII. PEG VIII. Biotin- $g$-lysine-co-PEG IX. NADES-Biotin- $g$-lysine-co-PEG
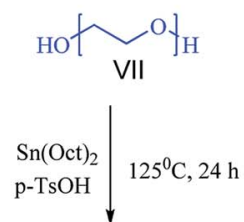<smiles>CC(O)C(=O)O</smiles><smiles>CCOC(=O)[C@@H](N)CCCCNC(=O)CCCC[C@@H]1SC[C@@H]2NC(=O)N[C@H]12</smiles>
III Stirrer, $1 \mathrm{~h} \downarrow 27^{\circ} \mathrm{C}$

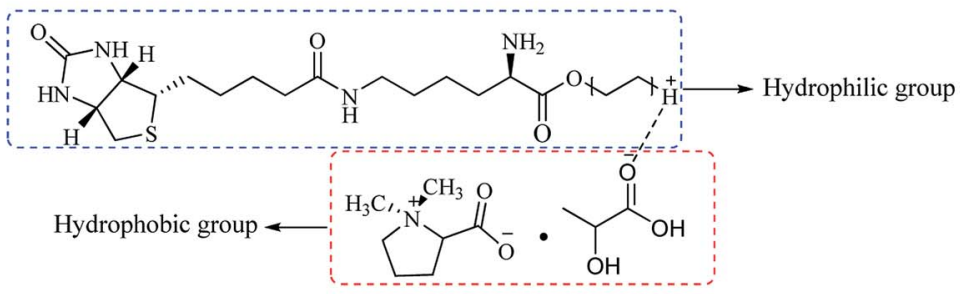

IX

Scheme 1 Schematic representation of (A) NADES synthesis and (B) synthetic route of the biotin-conjugated solid-liquid polymer. 
Table 2 The density of the NADESs ${ }^{a}$

\begin{tabular}{|c|c|c|c|c|}
\hline Code & Composition & $\begin{array}{l}\text { Temperature } \\
\left({ }^{\circ} \mathrm{C}\right)\end{array}$ & $\begin{array}{l}\text { Density ( } \mathrm{g} \\
\left.\mathrm{cm}^{-3}\right)\end{array}$ & Observation (RT) \\
\hline 1 & PB : LA (1: 1) & 27 & 1.1571 & Semisolid \\
\hline 2 & PB : LA (1:2) & 27 & 1.1425 & Transparent liquid \\
\hline 3 & PB : LA (1:3) & 27 & 1.1713 & Highly viscous \\
\hline 4 & PB : LA (2: 1) & 27 & 1.1358 & Semisolid \\
\hline
\end{tabular}

\section{Density analysis}

Solvent density plays a critical role in chemical synthesis, and it is an essential physical property. In drug carrier synthesis using ILs, DES, and NADES, density plays a significant role in the formation of drug delivery systems (DDSs). ${ }^{29}$ The densities of the NADES- $1: 1$, NADES- $1: 2$, NADES- $1: 3$, and NADES- $2: 1$ solvents are mentioned in Table 2 . The NADES density values ranged from 1.1571 to $1.1713 \mathrm{~g} \mathrm{~cm}^{-3}$ at room temperature $\left(27^{\circ} \mathrm{C}\right)$. NADES-1:3 had the maximum density $\left(1.1713 \mathrm{~g} \mathrm{~cm}^{-3}\right)$ at $27^{\circ} \mathrm{C}$. As the concentration of LA increased, simultaneously the molecular kinetic energy also increased because of the vibration of the atoms which were available in the NADES. It is seen that since the mobility of the NADES improved, the densities of the solvent decreased.

\section{NMR analysis}

The interaction of the PB: LA-based NADES formation was examined by using ${ }^{1} \mathrm{H}$ - and ${ }^{13} \mathrm{C}-\mathrm{NMR}$ to confirm the structure. The HBA of PB characteristic signal of ${ }^{1} \mathrm{H}$ values: $4.23(\mathrm{t}, \mathrm{CH})$, $3.05\left(\mathrm{~s}, 2 \mathrm{CH}_{3}\right), 3.00\left(\mathrm{q}, \mathrm{CH}_{2}\right), 2.01\left(\mathrm{p}, \mathrm{CH}_{2}\right), 1.83\left(\mathrm{q}, \mathrm{CH}_{2}\right)$ and ${ }^{13} \mathrm{C}$ NMR values: $185,93,55,43$, and 28 (ESI Fig. $3 \dagger$ ). The HBD of LA showed ${ }^{1} \mathrm{H}$ NMR values: $4.67(\mathrm{~s}, \mathrm{OH}), 4.11(\mathrm{~s}, \mathrm{OH}), 1.47$ (d, 3H), $1.11(1,1 \mathrm{H})$, and ${ }^{13} \mathrm{C}$ NMR values: $185,70,25$ (ESI Fig. $4 \dagger$ ). After the interaction of PB : LA (NADES-1:2) ${ }^{1} \mathrm{H}$ values: $10.73(\mathrm{~s}, 1 \mathrm{H})$, 5.21 (q, $\mathrm{CH}_{2}$ ), 4.21 (q, $\left.\mathrm{CH}_{2}\right), 3.36\left(\mathrm{~s}, 2 \mathrm{CH}_{2}\right), 3.42\left(\mathrm{q}, \mathrm{CH}_{2}\right), 2.56$ (s, $1 \mathrm{H}), 1.81\left(\mathrm{p}, \mathrm{CH}_{2}\right), 1.79\left(\mathrm{p}, \mathrm{CH}_{2}\right), 0.8\left(\mathrm{~s}, \mathrm{CH}_{2}\right)$ and ${ }^{13} \mathrm{C} \mathrm{NMR}$ values: $170,89,77,75,58,28$, and 26 (ESI Fig. $5 \dagger$ ). In ESI Fig. $6, \dagger$ the formation of NADES-1:3 characteristic signal of the ${ }^{1} \mathrm{H}$ NMR values: $10.71(\mathrm{~s}, 1 \mathrm{H}), 6.51\left(\mathrm{q}, \mathrm{CH}_{2}\right), 5.51\left(\mathrm{q}, \mathrm{CH}_{2}\right), 4.45\left(\mathrm{~s}, 2 \mathrm{CH}_{2}\right)$, 4.01 (q, $\mathrm{CH}_{2}$ ), 4.00 (s, 1H), 2.71 (p, $\left.\mathrm{CH}_{2}\right), 2.62$ (p, $\left.\mathrm{CH}_{2}\right), 2.01$ (s, $\mathrm{CH}_{2}$ ) and ${ }^{13} \mathrm{C}$ NMR values: $173,93,79,78,56,27$, and 24 . The spectral results show that the hydrogen bonding of $\left(\mathrm{O}-\mathrm{H}^{+} \cdots-\mathrm{O}\right)$ group is indicative of interaction with HBA and HBD in NADES formation (Fig. S2C $\dagger$ ). The characteristic ${ }^{1} \mathrm{H}$ signals of NADES were shifted downfield when compared with free PB and LA, which is a result of excellent hydrogen bond interaction of NADES. ${ }^{35}$

\section{FT-IR analysis}

PB, LA, NADES, biotin- $g$-lysine-co-PEG polymer, and PTX- and 7HC-loaded NADES-based biotin-conjugated solid-liquid polymer nanocarrier were characterized by FT-IR spectroscopy. The results are shown in Fig. 1. Fig. 1A shows the absorption bands of $\mathrm{PB}$ functional groups at $1355 \mathrm{~cm}^{-1}$ (-CH stretching vibration) and $1612 \mathrm{~cm}^{-1}$ (carbonyl stretching vibrations). Fig. 1B shows the LA moiety characteristic peaks at 3570,1726 , and $1081 \mathrm{~cm}^{-1}$ corresponding to the $\mathrm{OH}, \mathrm{C}-\mathrm{O}$, and $\mathrm{C}-\mathrm{C}$ group vibration peaks. Fig. 1C and D present the typical spectra of NADES-1:2 and NADES-1:3 solvents. The COO-, $\mathrm{C}-\mathrm{O},-\mathrm{CH}$ and $\mathrm{C}-\mathrm{C}$ bands were observed at $1360 \mathrm{~cm}^{-1}, 1635 \mathrm{~cm}^{-1}, 1646 \mathrm{~cm}^{-1}, 1638 \mathrm{~cm}^{-1}, 755$ and $752 \mathrm{~cm}^{-1} \cdot{ }^{\mathbf{1 5 , 1 6}}$ Broad peaks were observed at 2934 and $3322 \mathrm{~cm}^{-1}$, which indicates that the hydroxyl group $(\mathrm{OH})$ was involved in strong intramolecular hydrogen bonding during NADES formation. Also, the new characteristic peaks of NADES confirm the interaction of LA and PB moiety. As shown in Fig. 1E, the peaks at $3295 \mathrm{~cm}^{-1}(\mathrm{O}-\mathrm{H}), 2935 \mathrm{~cm}^{-1}(\mathrm{C}-\mathrm{H})$, $1570 \mathrm{~cm}^{-1}(\mathrm{~N}-\mathrm{H}), 1378 \mathrm{~cm}^{-1}(\mathrm{C}-\mathrm{C}), 1690 \mathrm{~cm}^{-1}(\mathrm{C}=\mathrm{O})$, and $1378 \mathrm{~cm}^{-1}(\mathrm{C}-\mathrm{O})$ are revealed by biotin molecule. Fig. $1 \mathrm{~F}$ shows a strong peak at $1666 \mathrm{~cm}^{-1}$ corresponding to amide bonds and represents the amide bond of the biotin grafted lysine (biotin- $g$ lysine). ${ }^{17,36}$ The FT-IR spectrum of biotin- $g$-lysine-co-PEG (biotinconjugated solid-liquid polymer) (Fig. 1G) demonstrates characteristic peaks at 1596 and $1726 \mathrm{~cm}^{-1}$, which represent the amide and ester stretching vibration of PEG and biotin- $g$-lysine, respectively. ${ }^{37}$ The characteristic peaks at 1095, 1241, 1513, $1560,1651,1734,2940$, and $3376 \mathrm{~cm}^{-1}$ show a strong hydrophobic interaction between nanocarriers and drugs (PTX and 7$\mathrm{HC}$ ). All the characteristic peaks confirm the synthesis of PTXand 7-HC-loaded NADES-based biotin-conjugated solid-liquid polymer nanocarrier (Fig. 1H).

\section{XRD, Raman spectroscopy and TGA}

The XRD patterns and Raman spectra of biotin- $g$-lysine-co-PEG polymer, NADES-based biotin-conjugated solid-liquid polymer, and PTX- and 7-HC-loaded nanocarrier were studied. The XRD pattern of biotin-conjugated solid-liquid polymer nanocarrier exhibited peaks at $2 \theta$ values of $23.11,25.6,26.5,27.8,29.9$, $31.56,43.90,44,49.32,50.1,53.5$ and $56.0^{\circ}$, indicating the grafted polymer is semi-crystalline (Fig. 2a(A)). As shown in Fig. 2a(B), the intensity of the characteristic peaks was decreased due to the interaction between NADES biotin- $g$ lysine-co-PEG polymer in the formation of SLN, and the $2 \theta$ values are $15.41,22.47,25.71,31.70$, and $45.31^{\circ}$. PTX shows multiple peaks at $2 \theta$ values of $23,35,39.01,41.25,44.56,47.21$, and $66^{\circ}$ due to its crystalline nature (Fig. $\left.2 \mathrm{a}(\mathrm{C})\right){ }^{38}$ The XRD pattern of 7-HC exhibited peaks appearing at $2 \theta$ values of 28.15 , $30.15,31.39,32.20,33.83,44.37,46.00,54.92,62.23,65.83$, 67.52, and $69.97^{\circ}$ (Fig. 2a(D)). ${ }^{39}$ After encapsulation of both drugs in the SLN system, the XRD pattern shows broad, less intense peaks, with a minor shift. This indicates that the drugencapsulating SLN system has excellent interactions with a semi-crystalline nature (Fig. 2a(E)). Generally, a semicrystalline system has a good interaction with biological liquids, which may be fitting for penetration through tissue layers and might provide an excellent diffusion property for the nanocarriers with drug molecules. Since the nature of the PTXand 7-HC-loaded SLN system allows for interaction with the cell membranes, these materials have been used.

Raman spectra were investigated to study the interaction between PTX and 7-HC and SLN (Fig. 2b). The bands at 

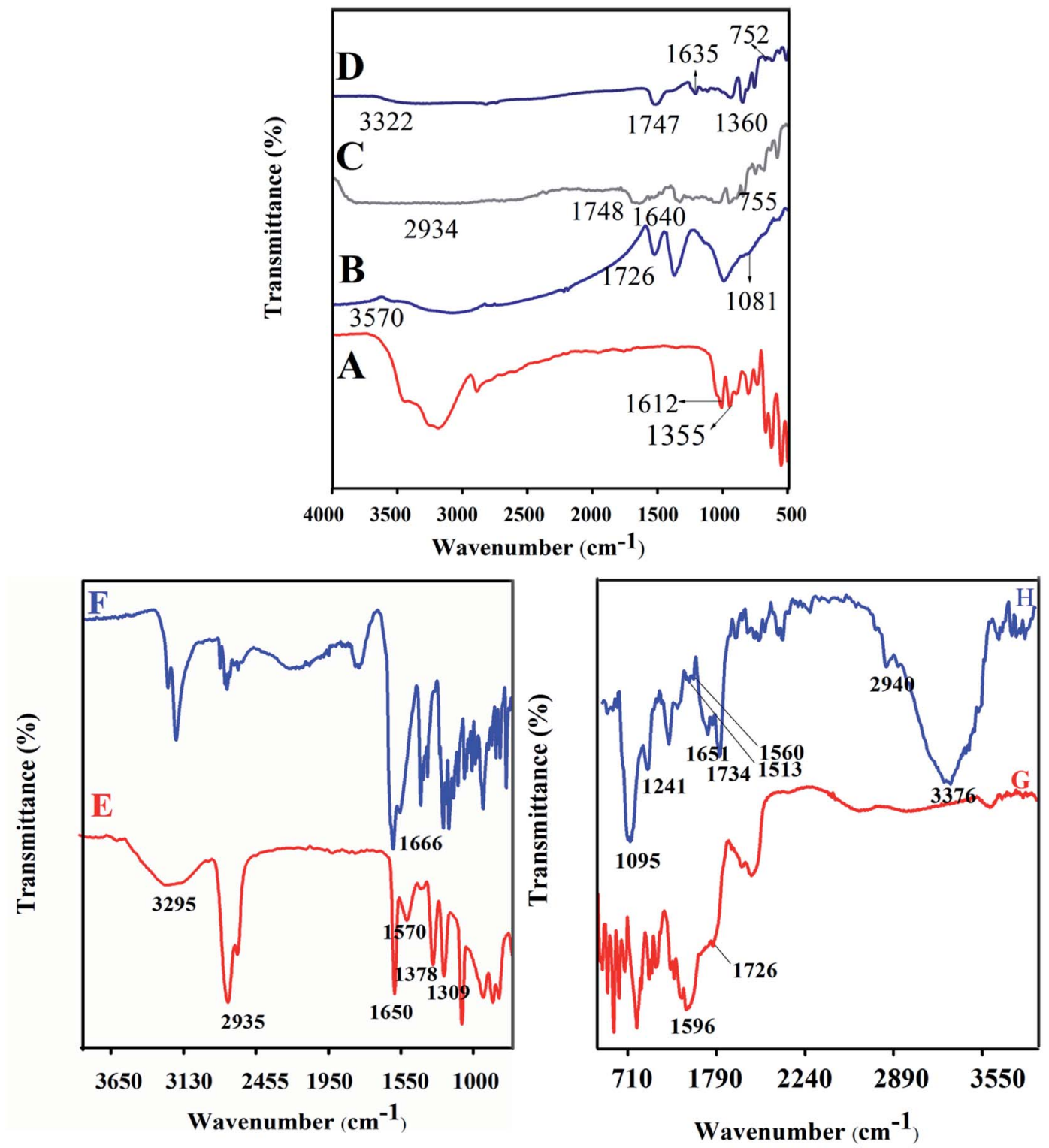

Fig. 1 FT-IR spectra of (A) prolinebetaine, (B) lactic acid, (C) NADES-1:2, (D) NADES-1:3, (E) biotin, (F) biotin-g-lysine, (G) biotin- $g$-lysine-co-PEG, and $(\mathrm{H})$ PTX- and 7-HC-loaded NADES-based biotin-conjugated solid-liquid polymer (PTX- and 7-HC-loaded nanocarrier).

$1126 \mathrm{~cm}^{-1}$ are assigned to the $\mathrm{C}-\mathrm{N}$ stretching vibration mode of $\mathrm{PB}$, and the band at $865 \mathrm{~cm}^{-1}$ is attributed to the strong $\mathrm{C}-\mathrm{COO}$ bending mode. ${ }^{26}$ The bands at $1319 \mathrm{~cm}^{-1}, 1371 \mathrm{~cm}^{-1}$, and $1069 \mathrm{~cm}^{-1}$ are attributed to the strong $\mathrm{CH}_{3}$ stretching mode. The band at $1680 \mathrm{~cm}^{-1}$ was assigned to the ester vibration mode. ${ }^{40}$ The characteristic vibration bands at $1680 \mathrm{~cm}^{-1}$ corresponded to the amide stretching vibration modes, as shown in Fig. 2b(A). Fig. 2b(B) shows the Raman spectrum of PTX- and 7-HC-loaded nanocarrier and vibration bands appeared at 278, 293, 309, 340, 366, 392, 926, 952, and $1066 \mathrm{~cm}^{-1}$. This reveals the durable hydrophobic nature and hydrophobic interaction between nanocarrier and drugs.

The thermal stability and decomposition of the unloaded and PTX- and 7-HC-loaded nanocarrier were characterized by TGA. Fig. 2c reveals PTX- and 7-HC-loaded nanocarrier degradation occurs as a multistep process compared with the nanocarrier alone. Thermal stability is a powerful force of molecules for bond energy and interactions. The TGA curve shows a slight decrease in the range of $25-35{ }^{\circ} \mathrm{C}$ and corresponds to the elimination of moisture in the nanocarrier (Fig. 2c(A)). The 2nd stage of weight reduction is from 150 to $165{ }^{\circ} \mathrm{C}$ due to $\mathrm{CO}$ and $\mathrm{CO}_{2},{ }^{41}$ and the third stage of weight loss from 320 to $350{ }^{\circ} \mathrm{C}$ is related to the decomposition of ester and amide linkages. In contrast, from the weight loss of PTX- and 7HC-loaded nanocarrier, it was found to have a higher thermal stability compared to the unloaded nanocarrier. At a temperature of $210{ }^{\circ} \mathrm{C}$, the mass had reduced by $85 \%$ in the carrier, followed by a gradual reduction of weight at $400-500{ }^{\circ} \mathrm{C}$ (Fig. 2c(B)). 

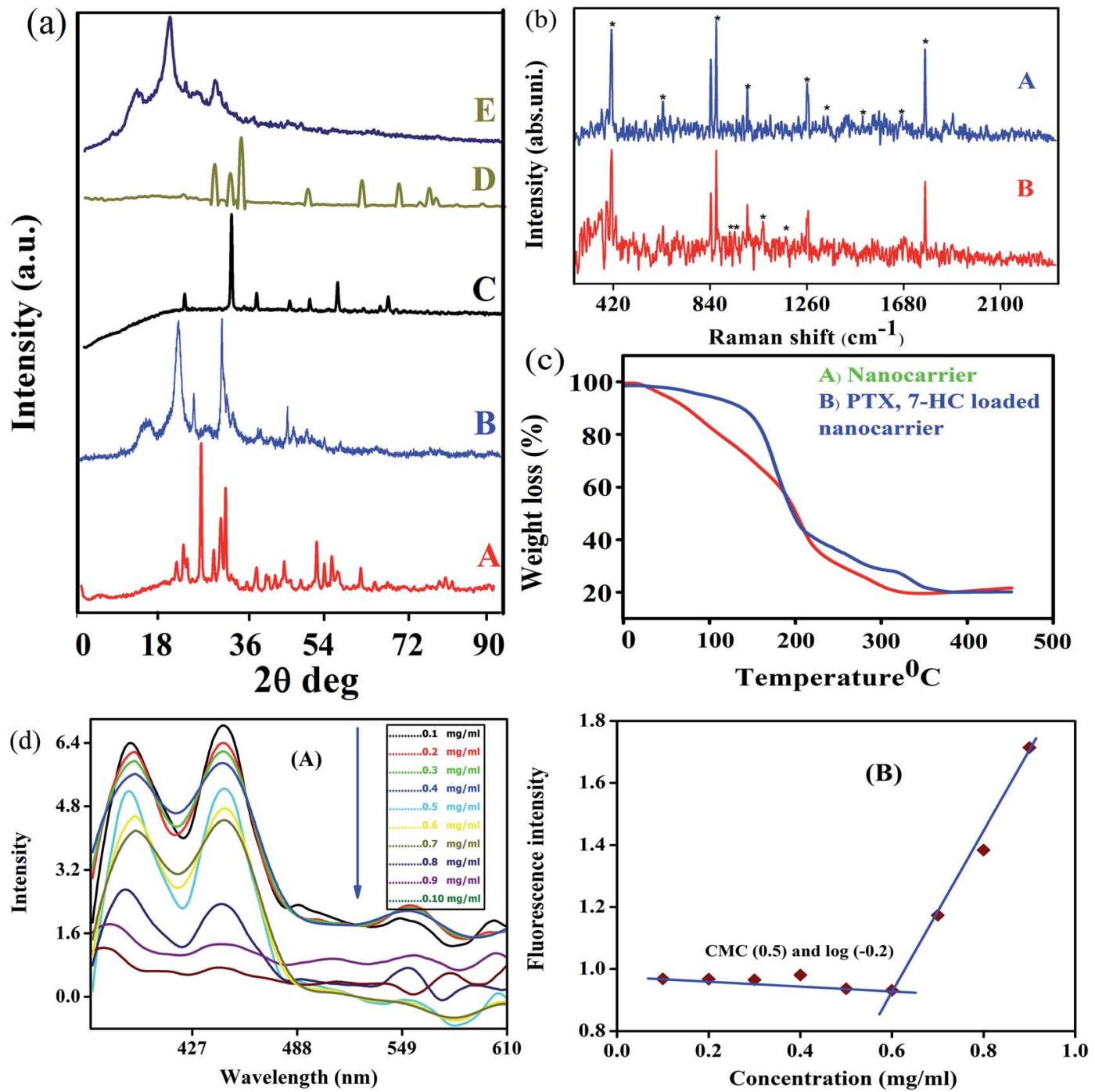

Fig. 2 (a) XRD patterns of (A) biotin-conjugated solid-liquid polymer, (B) NADES-based biotin-conjugated solid-liquid polymer, (C) PTX, (D) 7HC, and (E) PTX- and 7-HC-loaded nanocarrier. (b) Raman spectra of (A) nanocarrier and (B) PTX- and 7-HC-loaded nanocarrier. (c) TGA measurements for (A) nanocarrier and (B) PTX- and 7-HC-loaded nanocarrier. (d) Fluorescence spectra of micelles (A) intensity ratio $I_{1} / I_{3}$ of pyrene as a function of nanocarrier concentration, and (B) the CMC in an aqueous medium is determined to be about $0.6 \mathrm{mg} \mathrm{mL}^{-1}$.

\section{Determination of self-assembly of carrier formation}

The assistance of NADES enabled the synthesis of the NADESbased biotin-conjugated solid-liquid polymer nanocarrier through self-assembly. Here, the biotin-conjugated solid-liquid polymer nanocarrier acted with hydrophilic character and NADES with hydrophobic character, and it was a self-assembled from a solid-liquid polymeric system by dialysis. The selfassembling of the NADES-based biotin-conjugated solidliquid polymer system was confirmed through critical nanocarrier concentration using pyrene as a fluorescent probe. The first and third shift of the NADES-based biotin-conjugated solid-liquid polymer nanocarrier $\left(0.1 \mathrm{mg} \mathrm{mL}^{-1}\right)$ was found in the range of $I_{390} / I_{445}$, respectively. The final concentration of the NADES-based biotin-conjugated solid-liquid polymer nanocarrier $\left(0.9 \mathrm{mg} \mathrm{mL}^{-1}\right)$ was observed at $I_{377} / I_{442}$. The shifting of the higher region to lower one by changing the concentrations confirmed the amphiphilic polymer changes (Fig. 2d). The CMC value of NADES-based biotin-conjugated solid-liquid polymer nanocarrier was identified in the aqueous medium and observed at $0.6 \mathrm{mg} \mathrm{mL}^{-1}$.

\section{Surface morphological analysis}

The size determination and morphological characterization of the nanocarrier were conducted by SEM and TEM instrumental techniques (Fig. 3a). The surface feature of the carrier system can enhance the bio-distribution and pharmacokinetics of drugs in biological systems, and it has a vital role in the treatment of the diseases. ${ }^{42}$ Fig. $3 \mathrm{a}(\mathrm{A})$ shows that the nanocarrier is spherical, its size is increased with the incorporation of drugs and it is semi-crystalline. The SLN particle observed in the SEM image showed that the NADES liquid was covering to stabilize of the solid particle, and the solid portion 
(a)
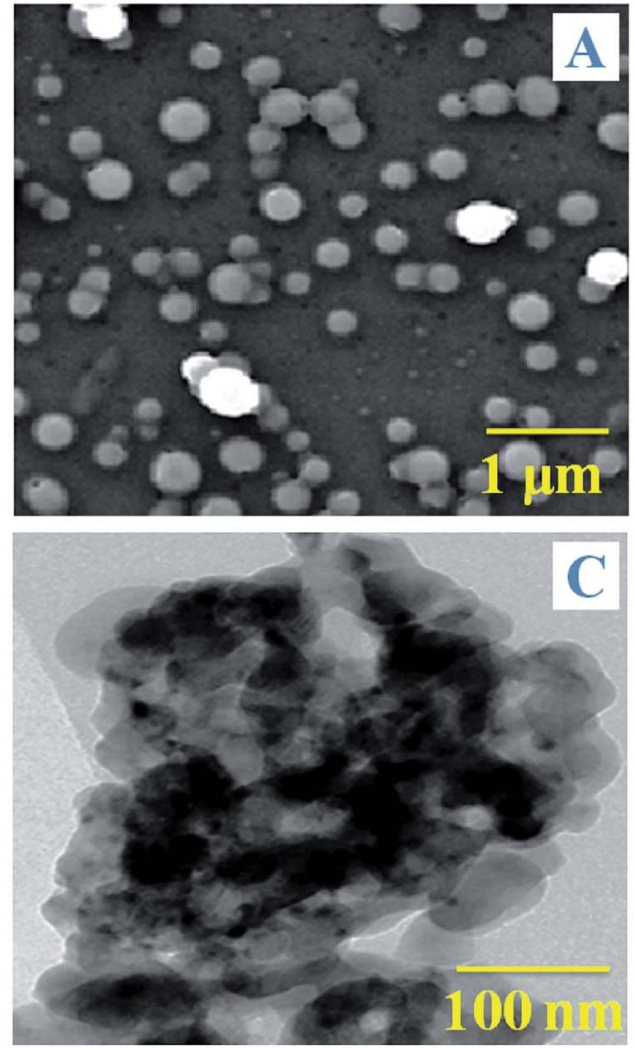

(b)

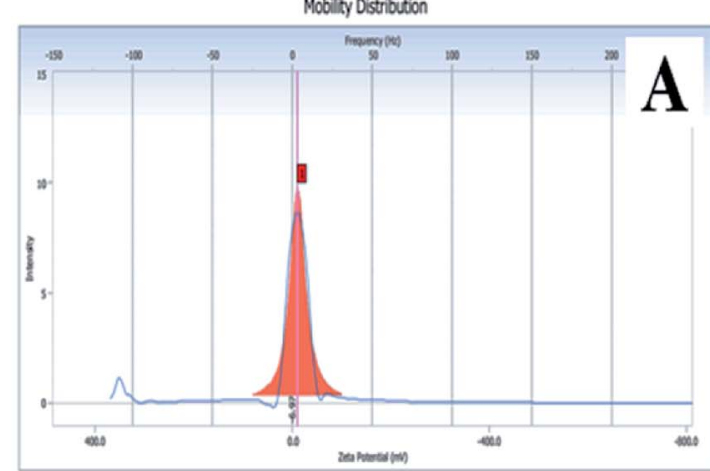

Intensity Distribution

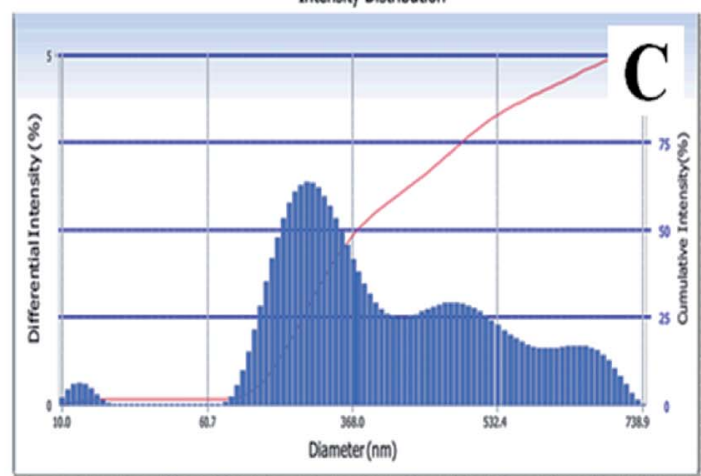

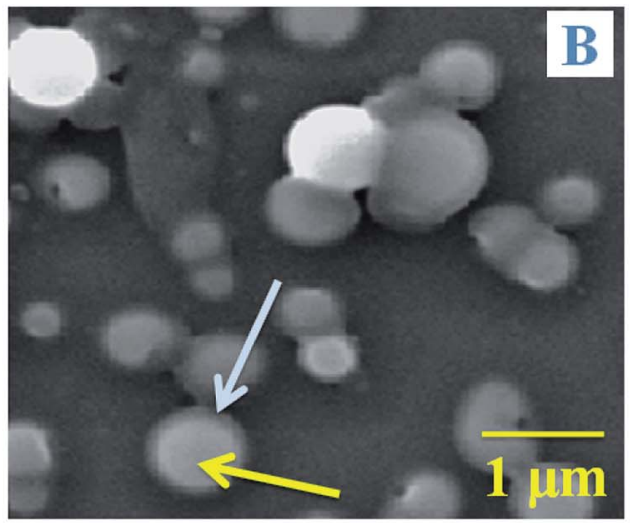

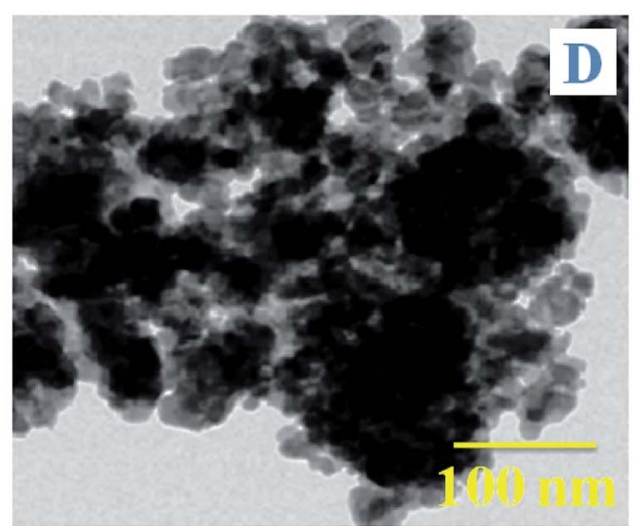

Mobility Oistritution

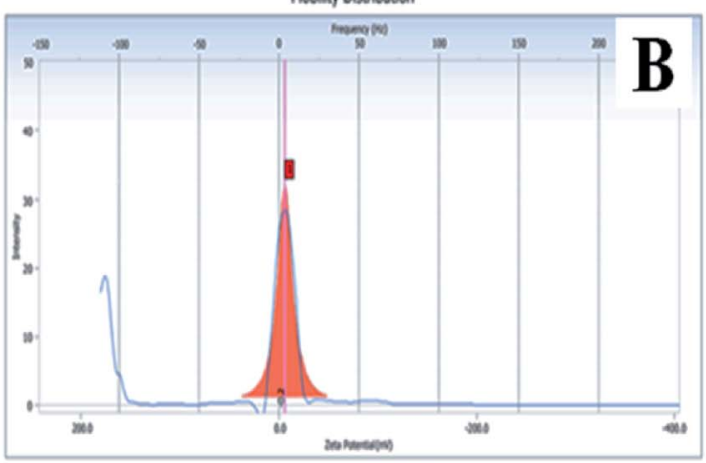

Intensity Distribution

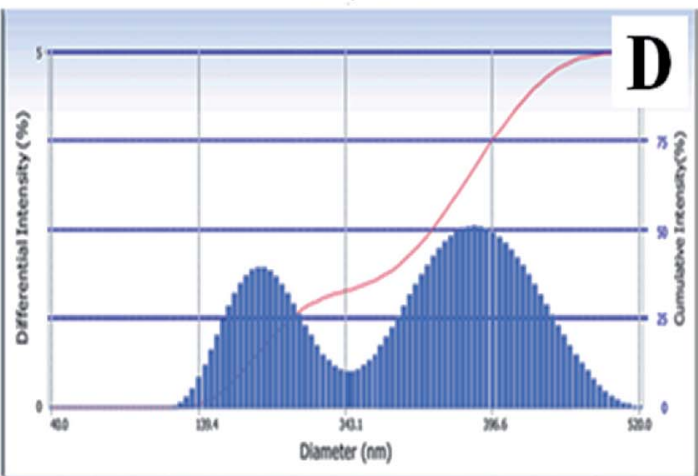

Fig. 3 (a) SEM images of (A) nanocarrier and (B) PTX- and 7-HC-loaded nanocarrier. TEM images of (C) nanocarrier and (D) PTX- and 7-HCloaded nanocarrier. The blue arrow indicates the hydrophilic outer layer, and the yellow arrow indicates the hydrophobic inner layer. (b) Zeta potential of (A) nanocarrier and (B) PTX-and 7-HC-loaded nanocarrier, and particle size of (C) nanocarrier and (D) PTX-and 7-HC-loaded nanocarrier. 
was highly dense in the drug-loaded SLN system (Fig. 3a(B)). Furthermore, the PTX- and 7-HC-loaded nanocarrier was spherical, and the size of the particle increased due to the charged drug molecules. Fig. 3a(C and D) show representative TEM images of the nanocarrier, the particles of which are spherical with a mean particle size of 200-300 nm; this correlates well with the SEM images.

\section{Particle size analysis and zeta potential determinations}

The surface charge and particle size of the unloaded and PTXand 7-HC-loaded SLN system were tested using DLS, and the results are presented in Fig. $3 \mathrm{~b}$. The zeta potential was observed at $-3 \pm 0.5 \mathrm{mV}$ and $-0.2 \pm 0.5 \mathrm{mV}$ for unloaded and PTX- and 7HC-loaded SLN systems, respectively. From these observations, drug-loaded SLN had enhanced stability over the unloaded carrier, due to the interaction of the drugs and carrier molecules. The observed zeta potential was nearly zero (Fig. 3b(A and B)). The surface charge of the nanocarrier has a meaningful relevance for biological applications for stability, interaction with cells, and also tissues. ${ }^{43}$ The size distribution of the nanocarrier was observed in the range of $\approx 240 \mathrm{~nm}$ for the unloaded and $\approx 290 \mathrm{~nm}$ for the loaded carrier. This indicated that molecule size expanded as PTX and 7-HC were incorporated in the nanocarrier (Fig. $3 \mathrm{~b}(\mathrm{C}$ and $\mathrm{D})$ ).
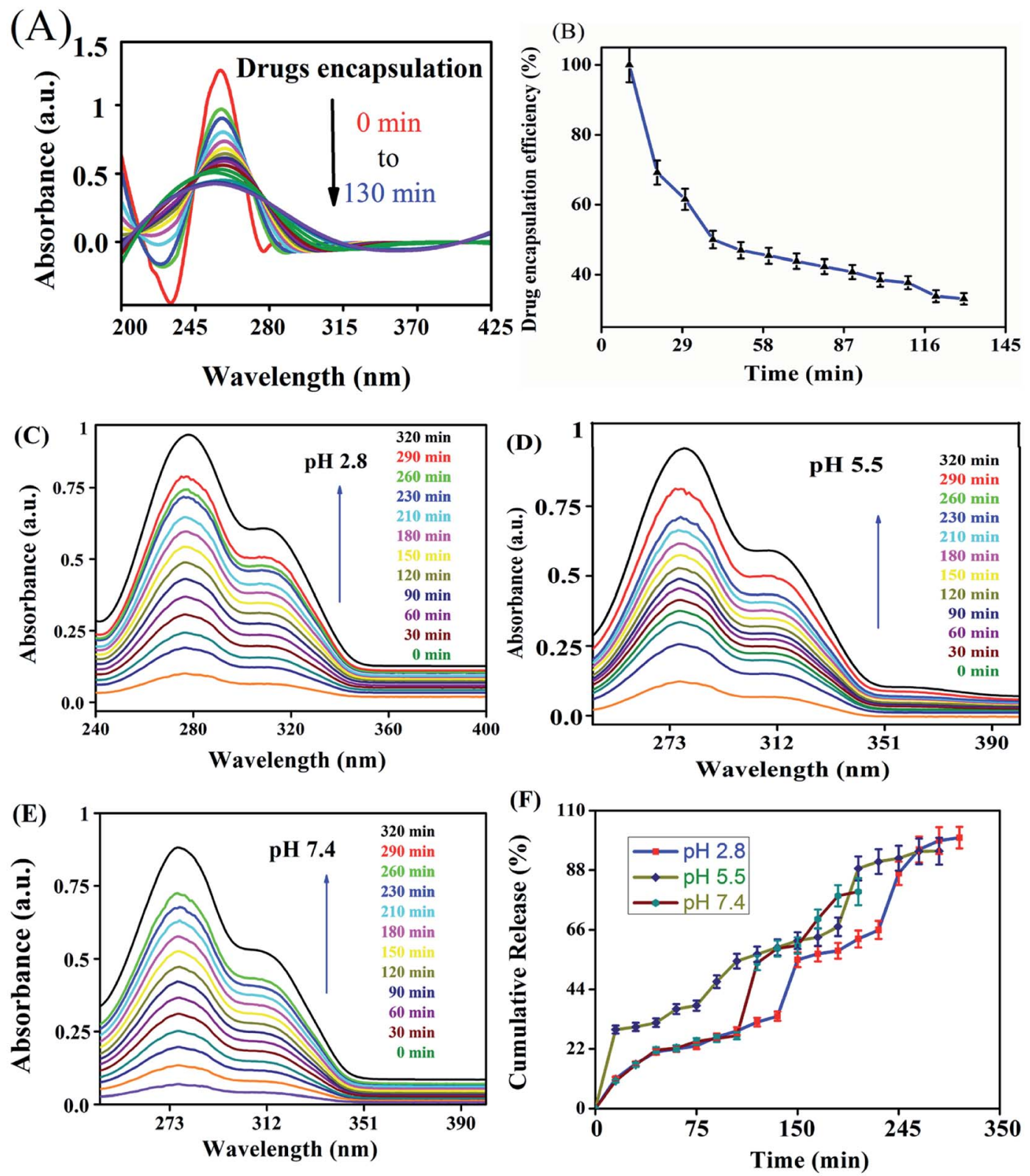

Fig. 4 UV-visible spectroscopy showing (A) encapsulation efficiency and (B) percentage encapsulation efficiency of PTX-and 7-HC-loaded nanocarrier. In vitro drug discharge status of PTX- and 7-HC-loaded nanocarrier at (C) pH 2.8, (D) pH 5.5, and (E) pH 7.4. (F) Cumulative drug release pattern over 320 min. 

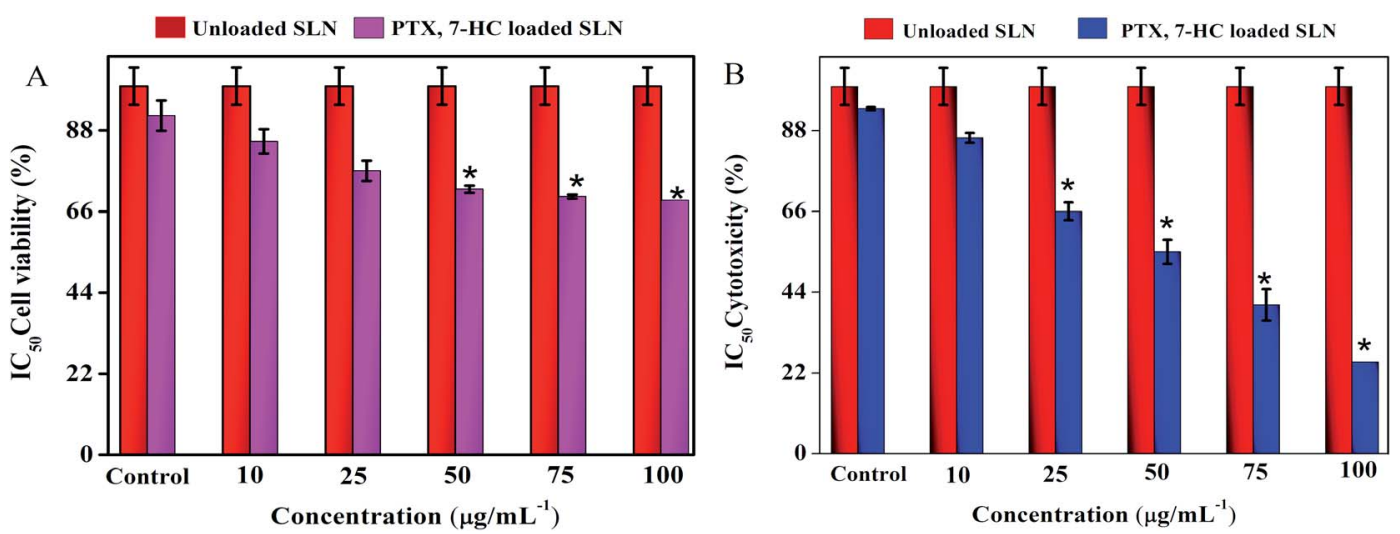

Fig. 5 (A) The cell viability of PTX- and 7-HC-loaded SLN-treated normal cell line. (B) The cytotoxicity of PTX-and 7-HC-loaded SLN against MDA-MB-231 cancer cell line.

\section{In vitro release}

The in vitro drug release profiles of anticancer drugs discharged from the nanocarrier were investigated for solutions at different pH by UV-visible spectroscopy (Fig. 4). The variation of drug release at different $\mathrm{pH}$ indicates that the carrier has $\mathrm{pH}$ dependent drug release. At an acidic $\mathrm{pH}$, a burst in drug release was observed when compared with other $\mathrm{pH}$ values. At pH 2.8, 27.47\% drug release was observed in the first $30 \mathrm{~min}$. On the other hand, at pH 7.4, only $8.79 \%$ was released from the carrier. The drug was released from the nanocarrier for up to $320 \mathrm{~min}$, with a maximum drug release at an acidic $\mathrm{pH}$ of 2.8 (97.0\%) compared with a pH of $7.4(89 \%)$ and pH $5.5(92 \%)$ within $320 \mathrm{~min}$. Burst releases followed by the increasing drug discharge pattern of the drugs from the carrier in a strongly acidic solution could be due to the amine group and ester easily protonating the nanocarrier in a strongly acidic environment compared with a nearly neutral pH solution.

\section{In vitro cell cytotoxicity}

The cytotoxic effect of SLN systems was estimated using a normal fibroblast cell line (L929) and a breast cancer cell line (MDA-MB-231) through the MTT assay for $24 \mathrm{~h}$ with various concentrations. The treatment of unloaded SLN and PTX- and 7HC-loaded SLN system retains cell viability in the normal fibroblast cell line (ESI Fig. 8A $\uparrow$ ), with quantitative cell viability being shown in Fig. 5A. ESI Fig. $8 \mathrm{~B} \dagger$ shows the viability of MDAMB-231 cells treated with unloaded and PTX- and 7-HC-loaded SLN. Viability decreased at a concentration of $100 \mu \mathrm{g} \mathrm{mL}^{-1}$, i.e., increased cell death was noticed when compared with the nanocarrier at lower concentrations; the cell cytotoxicity value of various concentrations is presented in Fig. 5B.

\section{Cellular uptake studies}

MDA-MB-231 breast cancer cells were cultured and treated with the PTX- and 7-HC-loaded SLN system for $24 \mathrm{~h}$ (Fig. 6).
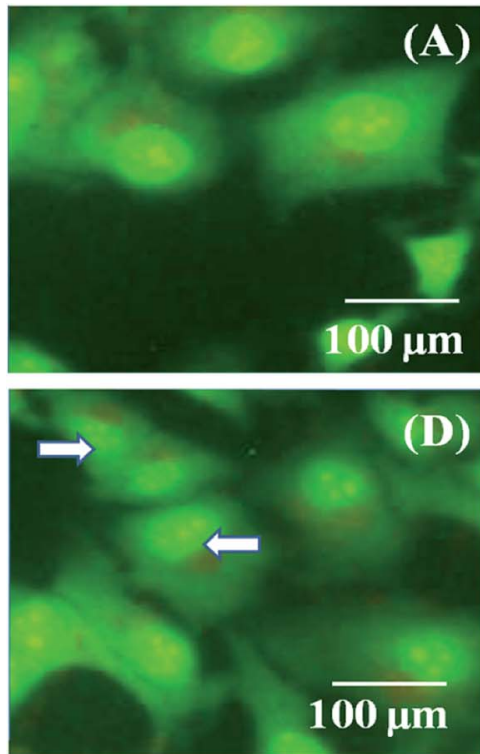
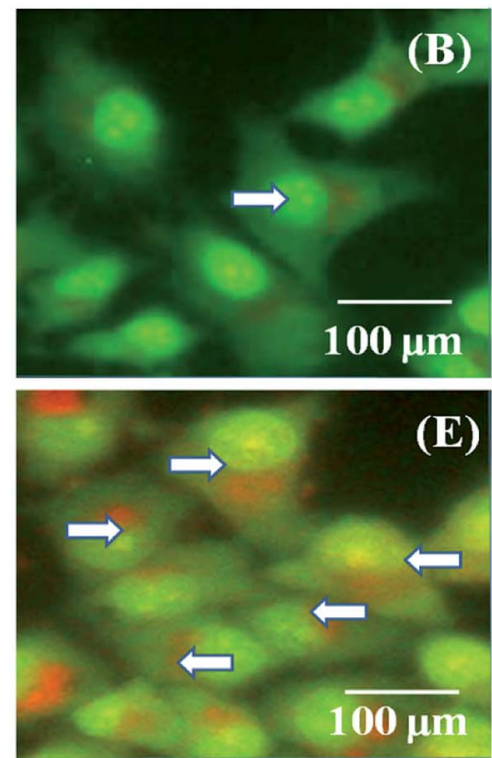
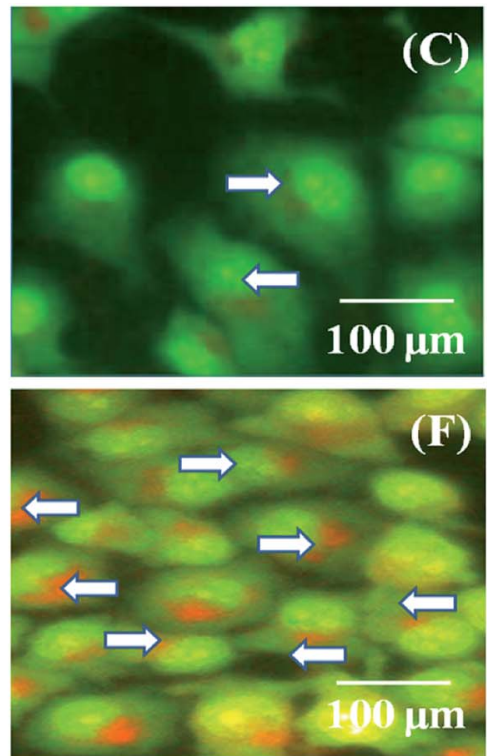

Fig. 6 Confocal images of MDA-MB-231 cancer cells incubated with PTX- and 7-HC-loaded SLN system at $27^{\circ} \mathrm{C}$ for (A) $1 \mathrm{~h}$, (B) $5 \mathrm{~h}$, (C) $10 \mathrm{~h}$, (D) $15 \mathrm{~h},(\mathrm{E}) 20 \mathrm{~h}$, and (F) $24 \mathrm{~h}$. White arrows indicate the presence of PTX- and 7-HC-loaded SLN around nuclei. 
Fluorescence images were observed after 1 h, 5 h, 10 h, 15 h, $20 \mathrm{~h}$, and $24 \mathrm{~h}$. As the treatment time increased, fluorescent intensities increased, which is due to a higher uptake of PTXand 7-HC-loaded carriers via receptor-mediated endocytosis. The fluorescence signal was very strong, and co-localization around the nucleus (white arrow) was observed at $20 \mathrm{~h}$ and $24 \mathrm{~h}$ in the PTX- and 7-HC-loaded SLN system-treated samples.

\section{In vivo studies}

Lysosomal enzymes. Fig. 7A presents the levels of lysosomal marker enzymes such as acid phosphatase, $\beta$-D-glucosaminidase, and cathepsin-D in plasma and mammary tissue of control and treated rats.

Effects of PTX- and7-HC-loaded SLN on caspase-3, -8 and -9 activities. To elucidate cell death induced by PTX- and 7-HCloaded SLN, the possible involvement of caspases was assessed (Fig. 7B).
Histological studies. The histological sections of breast tissue and liver tissue of DMBA-induced breast cancer in rats treated with $5 \mathrm{mg}$ per $\mathrm{g}$ b.wt of PTX- and 7-HC-loaded SLN are shown in Fig. 8. In both the liver and the mammary tissue sections, the loaded SLN-treated animals showed normal and healthy architecture when compared to the other groups.

\section{Discussion}

The SLN size was chosen based on tissue penetration, prolonged persistence in the bloodstream thereby avoiding renal filtration, and also better effectiveness for cancer therapy. As a result, the swelling behavior increased as the $\mathrm{pH}$ decreased. Moreover, the NADES-based biotin-conjugated solid-liquid polymer, after arriving at the targeted cancer cells, will be degraded by lysosomal enzymes that are abundant in cancer cells. The primary role of these enzymes is the degradation of ester and amide bonds. In this system, the drug carrier has both
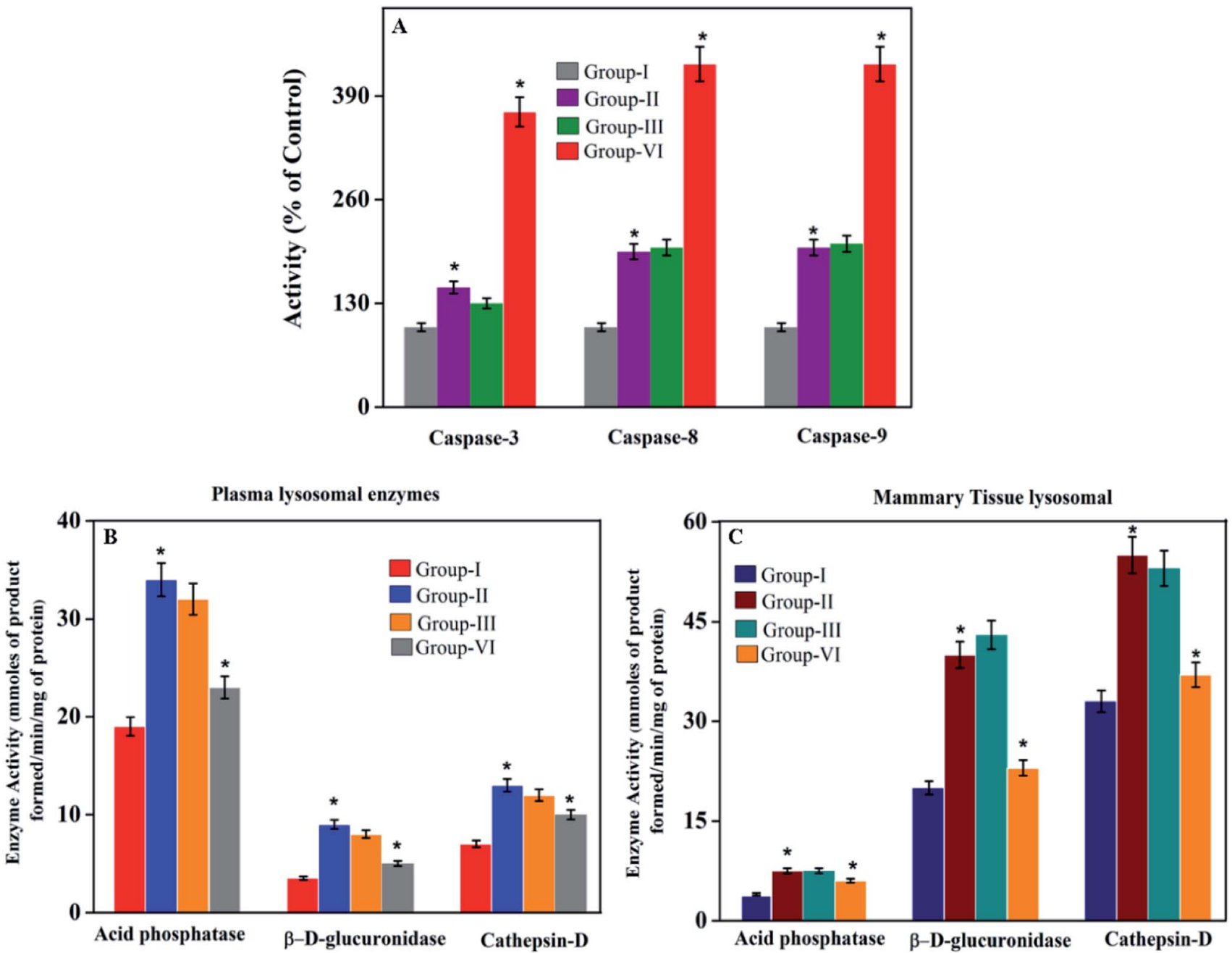

Fig. 7 (B and C) Effect of PTX- and 7-HC-loaded nanocarrier on lysosomal marker enzymes. Group I, control; group II, cancer induced; group III, SLN unloaded treated; group IV, SLN loaded treated. Each value is expressed as the mean \pm SD for six rats in each group. Significance compared to group I is shown as $* P<0.05$. (A) Effect of PTX- and 7-HC-loaded nanocarrier on caspase-3, -8, and -9. Group I, control; group II, cancer induced; group III, SLN unloaded treated; group IV, SLN loaded treated. Each value is expressed as the mean \pm SD for six rats in each group. Significant difference as compared to group I shown as $* P<0.05$. 


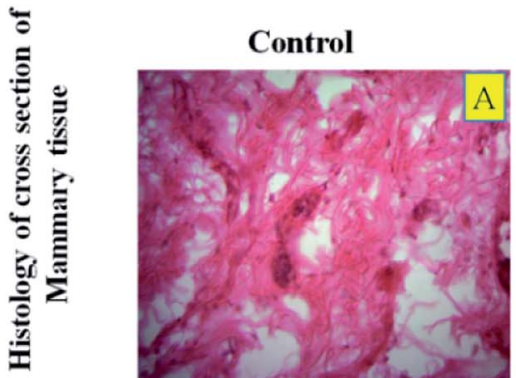

Control

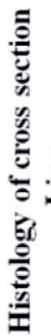

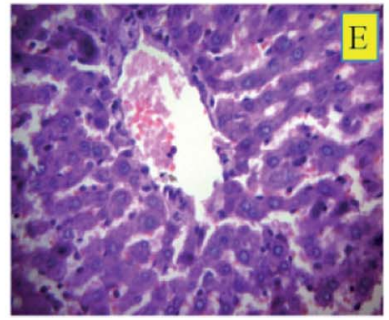

Induced

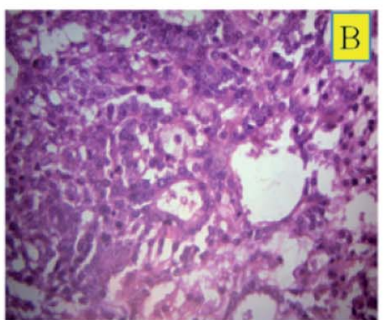

Induced

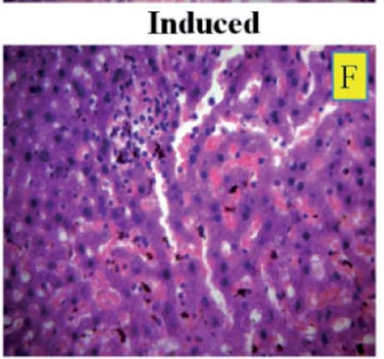

Treated 1

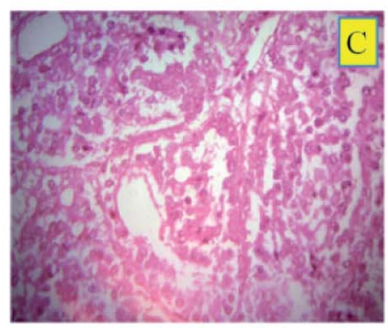

Treated 1

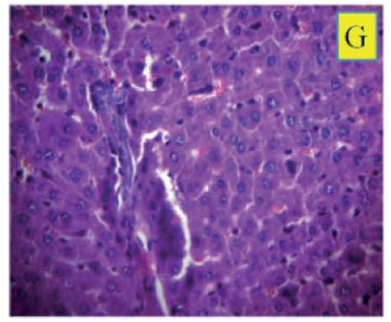

Treated 2

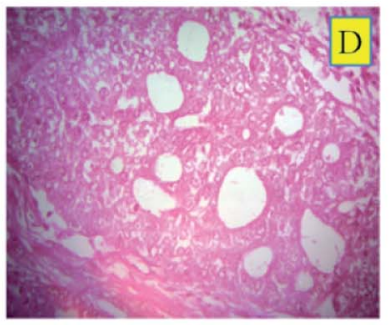

Treated 2

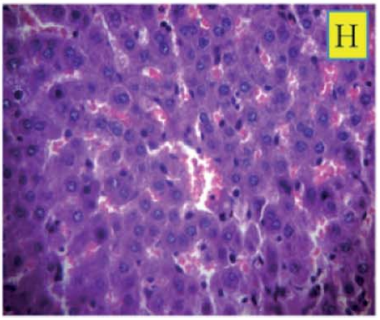

Fig. 8 Histological sections of mammary tissue of DMBA-induced breast cancer in rats from (A) control, (B) cancer induced, (C) SLN unloaded treated, and (D) SLN loaded treated. Liver sections of DMBA-induced breast cancer in rats from (E) control, (F) cancer induced, (G) SLN unloaded treated, and $(\mathrm{H})$ SLN loaded treated.

amide and ester bonds. The amide bonds found in the NADES will allow the lysosomal enzymes to simply degrade the biotinconjugated solid-liquid polymer in cancer cells. ${ }^{41}$ Thus, it will help the release of drugs into cancer cells. The cell cytotoxicity effect of the PTX- and 7-HC-loaded SLN is due to a high negative surface charge that eases the binding on the surface of cancer cells, thereby damaging the cell walls and altering adenosine triphosphate (ATP) production. Cell wall damage is the most significant determinant of the cytotoxic activity due to the strong electrostatic interaction involving the negatively charged polymer carrier and the positively charged cell membrane. ${ }^{44}$ Based on the cell uptake properties of the drug-loaded polymeric micelles, this suggests that PTX and 7-HC present in the nanocarrier interact with DNA and damage the nuclear membrane of cancer cells. ${ }^{38}$ From this, it could be seen that there are changes in the tumor volume and body weight, which are shown in Table 3. In cancer rats, the body weight was decreased $(P<0.05)$ as compared to the control rats. In PTX- and 7-HC-loaded SLN system-treated rats, the body weight was notably recovered and also the tumor size significantly reduced as compared with the cancer-induced and unloaded nanocarrier-treated rats. The lysosomal enzyme activities were significantly elevated (plasma and mammary tissue $(P<0.05))$ in group II animals when compared with the controls. This may be due to the abnormal release of lysosomes in cancer conditions. Also, the elevated levels could reflect the increased synthesis and secretion of lysosomal enzymes by tumors. ${ }^{35}$ Due to the treatment with PTX- and 7-HC-loaded SLN system in group IV animals, the enzyme levels decreased to near normal.

In most cases, different anticancer agents eventually mediate a common apoptotic pathway through the activation of caspases. The enzymatic activity of caspase- $3,-8$, and -9 in the PTXand 7-HC-loaded SLN-treated rats increased significantly. Otherwise, group II is a cancer-induced cell line. After that, the induced cell line was incubated with polymeric micelles, which gradually increased in group III due to the SLN's functional group activity in the cancer cell line. On the other hand, the caspase levels in the SLN-treated group remain unchanged. This reflects that the treatment with PTX- and 7-HC-loaded SLN leads to a strong cleavage of the biotin targeted molecules. However, the targeted drug delivery of PTX- and 7-HC-charged SLN to tumor cells excellently enhanced the apoptosis-induced cell death. The histological sections of PTX- and 7-HC-loaded SLNtreated rats reveal the presence of atrophy of seromucous

Table 3 Effect of nanocarriers on body weight and tumor volume in control and experimental rats ${ }^{a}$

\begin{tabular}{llcc}
\hline Body weight & Group I & Group II & Group III \\
\hline Initial & $199.5 \pm 8.26$ & $197.8 \pm 2.99$ & $198.6 \pm 5.39$ \\
Final & $239.5 \pm 4.33$ & $210.1 \pm 3.98^{*}$ & $212.7 \pm 4.85^{*}$ \\
Tumor volume & - & $4502 \pm 380^{*}$ & $4289 \pm 403^{*}$
\end{tabular}

$\left(\mathrm{mm}^{2}\right)$

${ }^{a}$ Group I, control; group II, cancer induced; group III, SLN unloaded treated; group IV, SLN loaded treated. Each value is expressed as the mean \pm SD for six rats in each group. Significance as compared to group I shown as ${ }^{*} P<0.05$. 
glands with surrounding stromal fibrosis, fatty tissue with small lobules, and tumor regression. DMBA-induced rats showed tumors composed of hyperchromatic, pleomorphic, vesicular nuclei, and moderate cytoplasm arranged in nests, sheets, and acinar structures with numerous mitotic structures. Based on the results, the PTX- and 7-HC-loaded SLN can reduce side effects. Ultimately, histological studies of the SLN and PTX- and 7-HC-loaded SLN did not reveal any abnormal morphological change to the mammary tissue and liver, further showing that they are safe for therapeutic use due to the PEG corona protecting against protein absorption with highly stable SLN and PTX- and 7-HC-loaded SLN, while the PEGylated surface led to an uptake in the liver.

\section{Conclusion}

A novel approach in advanced cancer prevention and treatment includes the use of SLN systems for anticancer drug delivery. A PTX- and 7-HC-loaded SLN was synthesized for the first time with a green solvent as a promising novel drug delivery system for the enhancement of the therapeutic index of cancer cells. The unloaded and PTX- and 7-HC-loaded SLNS were characterized in terms of size and crystalline properties. The higher toxicity of PTX- and 7-HC-loaded SLN system was observed by MTT assay, which promoted MDA-MB-231 cell death. The effect of PTX- and 7-HC-loaded SLN on cell viability was investigated with MTT assay and also by morphological observations. The decreased cell viability observed in this study could be due to direct inhibition of cell growth by PTXand 7-HC-loaded SLN. Apoptosis was included in cell death mechanisms observed in breast cancer-induced rats. Treatment with PTX- and 7-HC-loaded SLN system elevates caspase levels that stimulate cell death mechanisms and damage tumor tissue. From these results, it is clear that the synthesized PTX- and 7-HC-loaded SLN system is highly valuable in preventing cancer cell proliferation. It is concluded that the PTX- and 7-HC-packed SLN system might be a potential candidate for breast cancer treatment and also which can improve the treatment of incurable diseases. Additional studies are suggested for estimating the effect of these nanocarriers on other cell death mechanisms.

\section{Abbreviations}

$\begin{array}{ll}\text { NADES } & \text { Natural deep eutectic solvents } \\ \text { SLN } & \text { Solid-liquid nanocarrier } \\ \text { NMR } & \text { Nuclear magnetic resonance } \\ \text { FTIR } & \text { Fourier-transform infrared spectroscopy } \\ \text { TGA } & \text { Thermogravimetric analysis } \\ \text { XRD } & \text { Powder X-ray diffraction } \\ \text { DLS } & \text { Dynamic light scattering } \\ \text { SEM } & \text { Scanning electron microscopy } \\ \text { TEM } & \text { Transmission electron microscopy } \\ \text { PTX } & \text { Paclitaxel } \\ \text { 7-HC } & \text { 7-Hydroxycoumarin } \\ \text { MDA-MB-231 } & \text { M. D. Anderson and metastasis breast cancer }\end{array}$

$\begin{array}{ll}\text { PB } & \text { Prolinebetaine } \\ \text { LA } & \text { Lactic acid } \\ \text { b.wt } & \text { Bodyweight } \\ \text { DMBA } & \text { 7,12-Dimethylbenz[ } a] \text { anthracene } \\ \text { DDSs } & \text { Drug delivery systems } \\ \text { ILs } & \text { Ionic liquids } \\ \text { DESs } & \text { Deep eutectic solvents } \\ \text { DD water } & \text { Double-distilled water } \\ \text { ATP } & \text { Adenosine triphosphate } \\ \text { RT } & \text { Retention time }\end{array}$

\section{Conflicts of interest}

The authors declare that they have no competing interests.

\section{Acknowledgements}

M. Rajan is grateful for financial support under the plan of "ICMR" (F. No. 5/3/8/350/2018-ITR; New Delhi, India) and Department of Science and Technology, Science and Engineering Research Board (Ref: YSS/2015/001532; New Delhi, India) and also acknowledges the PURSE program for the purchase of SEM and FT-IR and UPE programs for the purchase of TEM. The authors extend their appreciation to the researchers supporting project number RSP-2020/190, King Saud University, Riyadh, Saudi Arabia.

\section{References}

$1 \mathrm{~J}$. Brindha and C. Kaushik, Evolutionary approaches in protein engineering towards biomaterial construction, $R S C$ Adv., 2019, 9, 34720-34734.

2 S. Mehnath, M. Arjama, M. Rajan, K. Premkumar, K. Karthikeyan and M. Jeyaraj, Mineralization of bioactive marine sponge and electrophoretic deposition on Ti-6Al-4V implant for osteointegration, Surf. Coat. Technol., 2020, 392, 125727.

3 F. Khan, M. Tanaka and S. R. Ahmad, Fabrication of Polymeric Biomaterials: A Strategy for Tissue Engineering and Medical Devices, J. Mater. Chem. B, 2015, 3, 8224-8249.

$4 \mathrm{H}$. H. Tonnesen and J. Karlsen, Alginate in Drug Delivery Systems, Drug Dev. Ind. Pharm., 2002, 28, 621-630.

5 S. Palvai, L. Anandi, S. Sarkar, M. Augustus, M. Roy, M. Lahiri and S. Basu, Drug-Triggered Self-Assembly of Linear Polymer into Nanoparticles for Simultaneous Delivery of Hydrophobic and Hydrophilic Drugs in Breast Cancer Cells, ACS Omega, 2017, 2, 8730-8740.

6 D. Govindaraj, P. Pradeepkumar and M. Rajan, Synthesis of morphology tuning multi mineral substituted apatite nanocrystals by novel natural deep eutectic solvents, Mater. Discovery, 2018, 9, 11-15.

7 N. Graf and S. J. Lippard, Redox Activation of Metal-Based Prodrugs as A Strategy for Drug Delivery, Adv. Drug Delivery Rev., 201, 264, 993-1004.

$8 \mathrm{Y}$. Ishihara and N. Shimamoto, Involvement of Endonuclease $\mathrm{G}$ in Nucleosomal DNA Fragmentation 
under Sustained Endogenous Oxidative Stress, J. Biol. Chem., 2006, 281, 6726-6733.

9 S. G. Arguelles, M. C. Serrano, M. C. Gutieerrez, M. Luisa Ferrer, L. Yuste, F. Rojo and F. del Monte, Deep Eutectic Solvents for the Self-Assembly of Gold Nanoparticles: A SAXS, UV-Vis, and TEM Investigation, Langmuir, 2013, 29, 9525-9534.

10 H. T. Thai Thanh, H. P. Emily, N. Dai Hai, S. L. Jung, P. Ki Dong and P. T. Nghia, The Importance of Poly(ethylene glycol) Alternatives for Overcoming PEG Immunogenicity in Drug Delivery and Bioconjugation, Polymers, 2020, 12, 298.

11 S. Ksenia, S. Egorova, G. Evgeniv, G. Gordeev and P. Valentine, Biological Activity of Ionic Liquids and Their Application in Pharmaceutics and Medicine, Chem. Rev., 2017, 117, 7132-7189.

12 P. Pradeepkumar, A. M. Elgorban, A. H. Bahkali and M. Rajan, Natural Solvent-Assisted Synthesis of Amphiphilic Co-Polymeric Nanonanocarrier for Prolonged Release of Camptothecin Delivery, New J. Chem., 2018, 42, 10366-10375.

13 R. Verpoorte, Chemodiversity and the Biological Role of Secondary Metabolites, Some Thoughts for Selecting Plant Material for Drug Development, in Bioassay Methods in Natural Product Research and Drug Development, ed. L. Bohlin and J. G. Bruhn, Proceedings of the Phytochemical Society of Europe, Springer, Dordrecht, 1999, vol. 43, pp. 11-23.

14 W. Czaban, J. Rasmussen, B. B. Laursen, N. H. Vidkjaer, R. Sapkota, M. Nicolaisen and S. Fomsgaard, Multiple Effects of Secondary Metabolites on Amino Acid Cycling in White Clover Rhizosphere, Soil Biol. Biochem., 2018, 123, 54-63.

15 S. Ksenia, S. Egorova, G. Evgeniv, G. Gordeev and P. Valentine, Biological Activity of Ionic Liquids and Their Application in Pharmaceutics and Medicine, Chem. Rev., 2017, 117, 7132-7189.

16 P. Pradeepkumar, D. Govindaraj, M. Jeyaraj, M. A. Munusamy and M. Rajan, Assembling of Multifunctional Latex-Based Hybrid Nanocarriers from Calotropisgigantea for Sustained (Doxorubicin) DOX Releases, Biomed. Pharmacother., 2017, 87, 461-470.

17 C. Mukesh, J. Bhatt and K. Prasad, Preparation of a NoncytotoxicHemocompatible Ion Gel by SelfPolymerization of HEMA in a Green Deep Eutectic Solvent, Macromol. Chem. Phys., 2014, 215, 1498-1504.

18 A. L. Wang, X. L. Zheng, Z. Z. Zhao, C. P. Li and X. F. Zheng, Deep Eutectic Solvent Catalyzed friedel-Crafts Alkylation of Electron-Rich Arenes with Aldehydes, RSC Adv., 2014, 5, 59022-59026.

19 D. Monleon, J. M. Morales, A. Barrasa, J. A. Lopez, C. Vazquez and B. Celd, Metabolite Profiling of Fecal Water Extracts From Human Colorectal Cancer, NMR Biomed., 2009, 22, 342-348.

20 C. R. Day and S. A. Kempson, Betaine Chemistry, Roles, and Potential Use in Liver Disease, Biochim. Biophys. Acta, Gen. Subj., 2016, 1860(6), 1098-1106.
21 S. S. Heinzmann, I. J. Brown, Q. Chan, M. Bictash, M. E. Dumas, S. Kochhar and J. Stamler, Metabolic profiling strategy for discovery of nutritional biomarkers: prolinebetaine as a marker of citrus consumption, Am. J. Clin. Nutr., 2010, 92, 436-443.

22 M. J. Joralemon, K. S. Murthy, E. E. Remsen, M. L. Becker and K. L. Wooley, Synthesis, Characterization, and Bioavailability of Mannosylated Shell Cross-Linked Nanoparticles, Biomacromolecules, 2004, 5, 903-913.

23 J. H. Kim, Y. Li, M. S. Kim, S. W. Kang, J. H. Jeong and D. Sung Lee, Synthesis and Evaluation of BiotinConjugated Ph-Responsive Polymeric Nanocarriers as Drug Carriers, Int. J. Pharm., 2012, 427, 435-442.

24 Y. Miyake, K. Yamamoto, Y. Morimitsu and T. Osawa, Isolation of C-Glucosylflavone from Lemon Peel and Antioxidative Activity of Flavonoid Compounds in Lemon Fruit, J. Agric. Food Chem., 1997, 45(12), 4619-4623.

25 V. S. Raghuwanshi, M. Ochmann, A. Hoell, F. Polzer and K. Rademann, Deep Eutectic Solvents for the Self-Assembly of Gold Nanoparticles: A SAXS, UV-Vis, and TEM Investigation, Langmuir, 2014, 30, 6038-6046.

26 W. Zhu, Z. Song, P. Wei, N. Meng, T. Teng, F. Yang, N. Liu and R. Feng, Y-Shaped Biotin-Conjugated Poly (Ethylene Glycol)-Poly (Epsilon-Caprolactone) Copolymer for The Targeted Delivery of Curcumin, J. Colloid Interface Sci., 2015, 443, 1-7.

27 A. S. Mikhail and C. Allen, (Poly(ethylene glycol)-b-poly( $(\varepsilon-$ caprolactone)) Nanocarriers Containing Chemically Conjugated and Physically Entrapped Docetaxel: Synthesis, Characterization, and the Influence of the Drug on Nanocarrier Morphology, Biomacromolecules, 2010, 11, 1273-1280.

28 R. A. Praphakar, M. A. Munusamy, A. A. Alarfaj, S. Suresh Kumar and M. Rajan, $\mathrm{Zn}^{2+}$ Cross-Linked Sodium AlginateG-AllylamineMannose Polymeric Carrier on Rifampicin for Macrophage Targeting Tuberculosis Nanotherapy, New J. Chem., 2017, 41, 11324-11334.

29 P. Pradeepkumar, R. Naresh Kumar, A. A. Alarfaj, M. A. Murugan and M. Rajan, Deep Eutectic SolventMediated FA-g- $\beta$-Alanine-co-PCL Drug Carrier for Sustainable and Site-Specific Drug Delivery, ACS Appl. Bio Mater., 2018, 1(6), 2094-2109.

30 C. Janas, Z. Mostaphaoui, L. Schmiederer, J. Bauer and M. G. Wacker, Novel Polymeric Nanocarriers for Drug Delivery: Material Characterization and Formulation Screening, Int. J. Pharm., 2016, 509, 197-207.

$31 \mathrm{~J}$. King, The hydrolases-acid and Alkaline Phosphatises, in Practical Clinical Enzymology, ed. J. C. King, D. Van Nostrand Company Ltd., London, 1965, pp. 191-208.

32 A. I. Sapolsky, R. D. Atlman, D. S. Howell and D. Cathepsin, Activity in Normal and osteoarthritic human cartilage, Fed. Proc., 1973, 32, 1489-1493.

33 Y. Kawai and K. Anno, Mucopolysaccharide Degrading Enzymes from the Liver of Squid OmmastrephesSolaniPacificus. I. Hyaluronidase, Biochim. Biophys. Acta, Enzymol., 1971, 242, 428-436. 
34 L. Servillo, N. D'Onofrio, A. Giovane, R. Casale, D. Cautela, G. Ferrari and D. Castaldo, The Betaine Profile of Cereal Flours Unveils New And Uncommon Betaines, Food Chem., 2018, 239, 234-241.

35 H. Shinar, M. D. Battistel, M. Mandler, F. Lichaa and F. L. Freed berg, Chemical Exchange Saturation Transfer NMR of Oligo- and Poly-Sialic Acids and the Assignment of Their Hydroxyl Groups Using Selective- and HSQC-TOCSY, Carbohydr. Res., 2014, 389, 165-173.

36 A. L. Wang, X. L. Zheng, Z. Z. Zhao, C. P. Li and X. F. Zheng, Deep Eutectic Solvent Catalyzed friedel-Crafts Alkylation of Electron-Rich Arenes with Aldehydes, RSC Adv., 2014, 5, 59022-59026.

37 C. Chien, T. Ching, A. Lin, M. Zhang, S. L. Levengood and M. Zhang, PEG-Chitosan Hydrogel with Tunable Stiffness for Study of Drug Response of Breast Cancer Cells, Polymers, 2016, 8, 112.

38 H. Zhang, H. Hu, H. Zhang, W. Dai, X. Wang, X. Wang and Q. Zhang, Effects of Pegylated Paclitaxel Nanocrystals On Breast Cancer and Its Lung Metastasis, Nanoscale, 2015, 7, 10790-10800.

39 G. A. Shtukenberg, Q. Zhu, D. J. Carter, L. Vogt, J. Hoja, E. Schneider and H. Song, Powder Diffraction and Crystal Structure Prediction Identify Four New Coumarin Polymorphs, Chem. Sci., 2017, 8, 4926-4940.
40 W. C. Harris and D. A. Coe, Vibrational spectra and structure of esters-H. ${ }^{*}$ Raman spectra and potential function calculations for $\mathrm{HCO0CH} 3, \mathrm{DCOOCH} 3$ and $\mathrm{HCOOCD}_{3}$, Spectrochim. Acta, Part A, 1976, 32, 1-10.

$41 \mathrm{H}$. Gheybi and A. A. Entezami, NanosizedNanocarriers Selfassembled from Amphiphilicpoly(citric acid)-poly(ecaprolactone)-poly(citric acid) Copolymers, Polym. Bull., 2013, 70, 1875-1894.

42 S. S. Davis, Biomedical Applications of NanotechnologyImplications for Drug Targeting and Gene Therapy, Trends Biotechnol., 1997, 15, 217-224.

43 K. Song Yang, N. V. Mai, H. P. Emily, P. R. J. Angus, R. W. Michael, F. Q. John, P. T. Nghia and P. D. Thomas, Elucidating the Influences of Size, Surface Chemistry, and Dynamic Flow on Cellular Association of Nanoparticles Made by Polymerization-Induced Self-Assembly, Small, 2018, 14(34), 1801702.

44 M. Rajan, P. Krishnan, P. Pradeepkumar, M. Jeyanthinath, M. Jeyaraj, M. P. Ling, P. Arulselvan, A. Higuchi, M. A. Munusamy, R. Arumugam, G. Benelli, K. Murugan and S. Suresh Kumar, Magneto-chemotherapy for cervical cancer treatment with camptothecin loaded $\mathrm{Fe}_{3} \mathrm{O}_{4}$ functionalizedb-cyclodextrinnanovehicles, RSC Adv., 2017, 7, 46271. 